\title{
EL ESTADO SEÑORIAL DE JORQUERA Y LA VILLA DE VES EN LA EDAD MODERNA A TRAVÉS DE FUENTES ECLESIÁSTICAS Y NOTARIALES
}

\section{THE MANORIAL ESTATE OF JORQUERA AND THE VILLAGE OF VES IN THE MODERN AGE THROUGH ECCLESIASTICAL AND NOTARIAL SOURCES}

\author{
Vicente Montojo Montojo \\ Real Academia Alfonso X el Sabio. \\ Archivero. Archivo General de la Región de Murcia \\ Murcia, España \\ vmontojo2@gmail.com
}

Cómo citar este artículo: Montojo Montojo, V. (2021). El estado señorial de Jorquera y la Villa de Ves en la Edad Moderna a través de fuentes eclesiásticas y notariales. Al-Basit (66), 97-139. http://doi.org/10.37927/al-basit.66_3

Recibido/Received: 13-02-2021

Aceptado/Accepted: 26-05-2021

RESUMEN: El objeto de este trabajo de investigación es el estudio de la evolución socioeconómica del estado señorial de Jorquera y la villa realenga de Ves y su tierra en documentos notariales y eclesiásticos de archivos como los históricos provinciales de $\mathrm{Al}$ bacete y Murcia y sobre todo del catedralicio de Murcia. Se tratan las relaciones económicas de sus pobladores con otras poblaciones del Reino de Murcia, a través de las actas de los registros de escribanos, y algunos problemas de la gestión del diezmo eclesiástico por medio de documentos del cabildo catedralicio de Murcia. Éstos permiten conocer alguna de
ABSTRACT: The object of this research work is the study of the socioeconomic evolution of the seigniorial state of Jorquera and the royal villa of Ves and its land in notarial and ecclesiastical documents from archives such as the provincial historical archives of Albacete and Murcia and above all from the cathedral of Murcia. The economic relations of its settlers with other towns of the Kingdom of Murcia are treated, through the minutes of the records of the notaries, and some problems of the management of the ecclesiastical tithe by means of documents of the cathedral chapter of Murcia. These allow 
las dificultades o tensiones con el marqués de Villena y duque de Escalona como señor del estado de Jorquera en torno al diezmo y a la distribución de las tercias, que hubo de extenderse a nuevas aldeas que surgieron en uno y otro sitio.

Por otra parte, las cuentas de diezmos del cabildo permiten confirmar la importancia de los cereales en la producción agraria de esta zona, algo que era previsible, pero también la contribución de productos como azafrán, queso y ganado, y de este sobre todo lanar.

Entre ambas fuentes eclesiásticas y notariales se percibe la presencia de propietarios de algunas heredades o haciendas vinculadas o amayorazgadas y otras no, es decir, libres, lo que permite comprobar la existencia de una sociedad compuesta de grandes, medianos y pequeños propietarios y por lo tanto diversa en su composición, sin el peso de tan gran número de jornaleros que se impuso avanzado el siglo XVIII.

PALABRAS ClAVE: Historia de Castilla-La Mancha, Historia Económica, Historia Moderna, Archivos, Fuentes documentales, La Manchuela de Albacete us to know some of the difficulties or tensions with the Marquis of Villena and Duke of Escalona as lord of the state of Jorquera around the tithe and the distribution of the tercias, which had to be extended to new villages that arose in both places.

On the other hand, the tithe accounts of the chapter confirm the importance of cereals in the agricultural production of this area, something that was foreseeable, but also the contribution of products such as saffron, cheese and cattle, especially sheep.

Between both ecclesiastical and notarial sources we can perceive the presence of owners of some estates or farms linked or amayorazgadas and others not, that is to say, free, which allows to verify the existence of a society composed of big, medium and small owners and therefore diverse in its composition, without the weight of so great number of day laborers that was imposed advanced the XVIII century.

KEYWORDS: History of CastileLa Mancha, Economic History, Modern History, Archives, Documentary sources, La Manchuela de Albacete

\section{INTRODUCCIÓN: ANTECEDENTES HISTÓRICOS}

Pretendo hacer en esta ocasión una aportación heurística (o de fuentes) y archivística, es decir, de ciencias historiográficas, a la historia socioeconómica del estado señorial de Jorquera y de la 
realenga villa de Ves, ambas poblaciones de la actual Provincia de Albacete y Comunidad de Castilla La Mancha, y comarca de La Manchuela albacetense, que engloba a la Tierra de Jorquera y a la de Ves. Ambas estuvieron situadas en el extremo norte del antiguo reino de Murcia (existente hasta 1833, aunque el nombre permaneció en la división provincial de Javier de Burgos para englobar las provincias de Albacete y Murcia) y en el marquesado de Villena y su partido de abajo (el de Chinchilla).

El estado de Jorquera lindó con los ríos Júcar y Cabriel y fue resultado de la Guerra del Marquesado (Cano, 1979; Franco, 1994), es decir, lo que le quedó al marqués de Villena en 1480 (Ortuño, 2002/2003; Franco, 2007), título de los Pacheco, originarios de Portugal, y aquél un residuo pequeño de lo mucho que tuvo. Villa de Ves y sus aldeas fue un territorio colindante al anterior, próximo al Júcar, pero realengo, ambos cercanos o situados en estribaciones del sistema prebético y entorpecidas por la Sierra del Mugrón para acceder a Almansa, y Alcalá del Júcar más próximo a Requena.

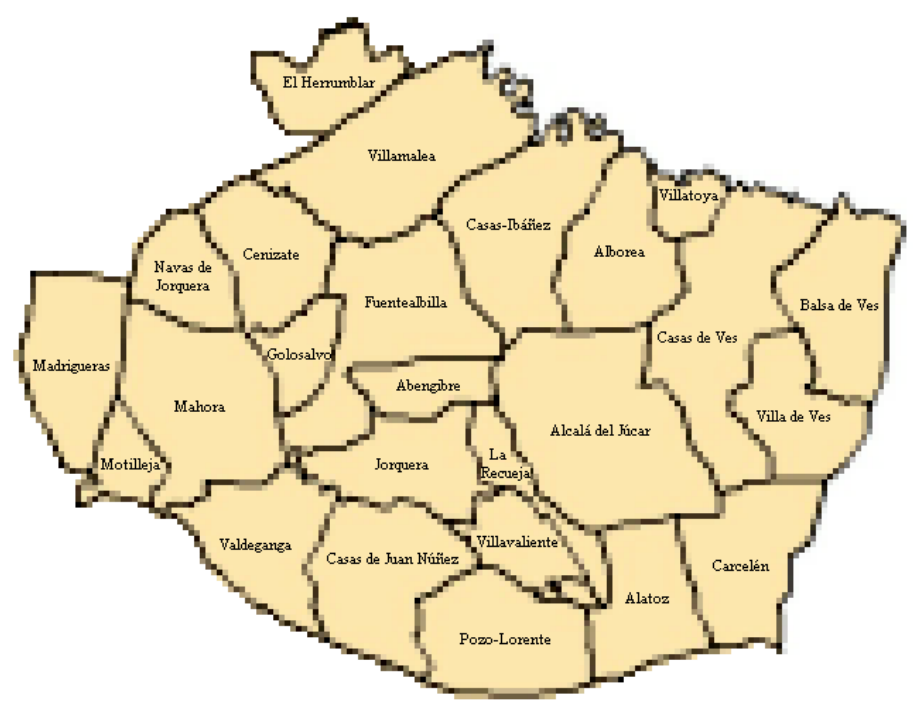

Mapa 1 MANCHUELA DE ALBACETE.

Espanish_AlB público, https://commons.wikimedia.org/w/index.php?curid=2424758 
Se pretende en este texto contribuir al conocimiento de la historia socioeconómica de estas poblaciones a través de fuentes documentales menos conocidas sobre estos territorios en los siglos XVI al XVIII (Edad Moderna), en archivos no municipales, como los históricos provinciales o el del cabildo catedralicio de Murcia, pero con respecto al conjunto de la población, no a un grupo o estamento concreto, y con un método archivístico. Para ello partiré del enfrentamiento del estado señorial de Jorquera y la villa de Ves, a lo largo de la Edad Moderna, a la sucesión de reclutamientos para defender las poblaciones costeras en el siglo XVII, hechos a pesar de su apartamiento o lejanía del centro del reino de Murcia $^{1}$ (Ortuño, 2003, p. 30-32).

Hubo una frecuente tensión ante el reclutamiento de tropas, pero cabe además plantearse: ¿Puede quizá decirse lo mismo de las exigencias económicas, como la entrega de tercias reales (tercera parte o 2 novenos del diezmo) y otras contribuciones?

El estado de Jorquera y la villa de Ves fueron encuadrados en el marquesado de Villena (Mitre, 1969; Martínez, 1987), pero este encuadramiento se hizo más difuso tras la conversión de los parti-

${ }^{1}$ Según Ruiz (1994, p. 112, 181, 193, 957 notas 23, 245, 280 y 283): «el propio Reino, entidad territorial clara y actualizada continuamente por el carácter representativo que del mismo tenía la ciudad de Murcia en las Cortes Castellanas. Resulta curiosa la no inclusión de las villas de Jumilla y Jorquera en el listado ofrecido por Alonso Enríquez de la voz de Murcia en las Cortes», o añade: «Incluso en Villena y Jorquera se produjo un «levantamiento» contra la compañía del capitán don Jorge Bernal Dávalos, lo que provocó la protesta generalizada. Se produjo una oposición a mano armada para impedir que dicho capitán pudiera formar su compañía voluntaria» (con la que socorrer la expedición naval contra Argel del conde de Niebla, 1603). Por lo tanto, una parte del marquesado de Villena se opuso a las exigencias militares de la corona. Y en 1611 Luís Fajardo excluyó al estado de Jorquera y al partido de Villanueva de los Infantes de la leva para el socorro de Orán: «Concretamente la oposición inicial se organizó de este modo: en el corregimiento de Chinchilla, corregidor don Ginés de Rocamora, suplicaron que no se cumplieran las órdenes: Albacete, Tobarra, Hellín, La Gineta, La Roda y Yecla; suplicaron que no se cumplieran pero obedeciéndolas: Almansa, Chinchilla y Villena; y suplicaron no cumplirlas por ser de señorío: Carcelén, Alpera y Montealegre», pero en 1646 Jorquera contribuyó al servicio de milicias con 3 soldados. 
dos alto y bajo (creados en 1480), en los corregimientos de Chinchilla de Montearagón y San Clemente (1586), el primero en el Reino de Murcia -pero el estado de Jorquera quedó en una posición marginal- y el segundo en el Obispado de Cuenca y Reino de Toledo. A ello repercutió la pertenencia de este espacio a la Diócesis de Cartagena (García, Irigoyen, García, 2002) y su contribución a su sostenimiento a través del diezmo eclesiástico, con destino al obispo, al cabildo catedralicio diocesanos, asentados en Murcia, y al rey (las tercias), cada uno de los cuales articuló unos poderes y generó unos archivos.

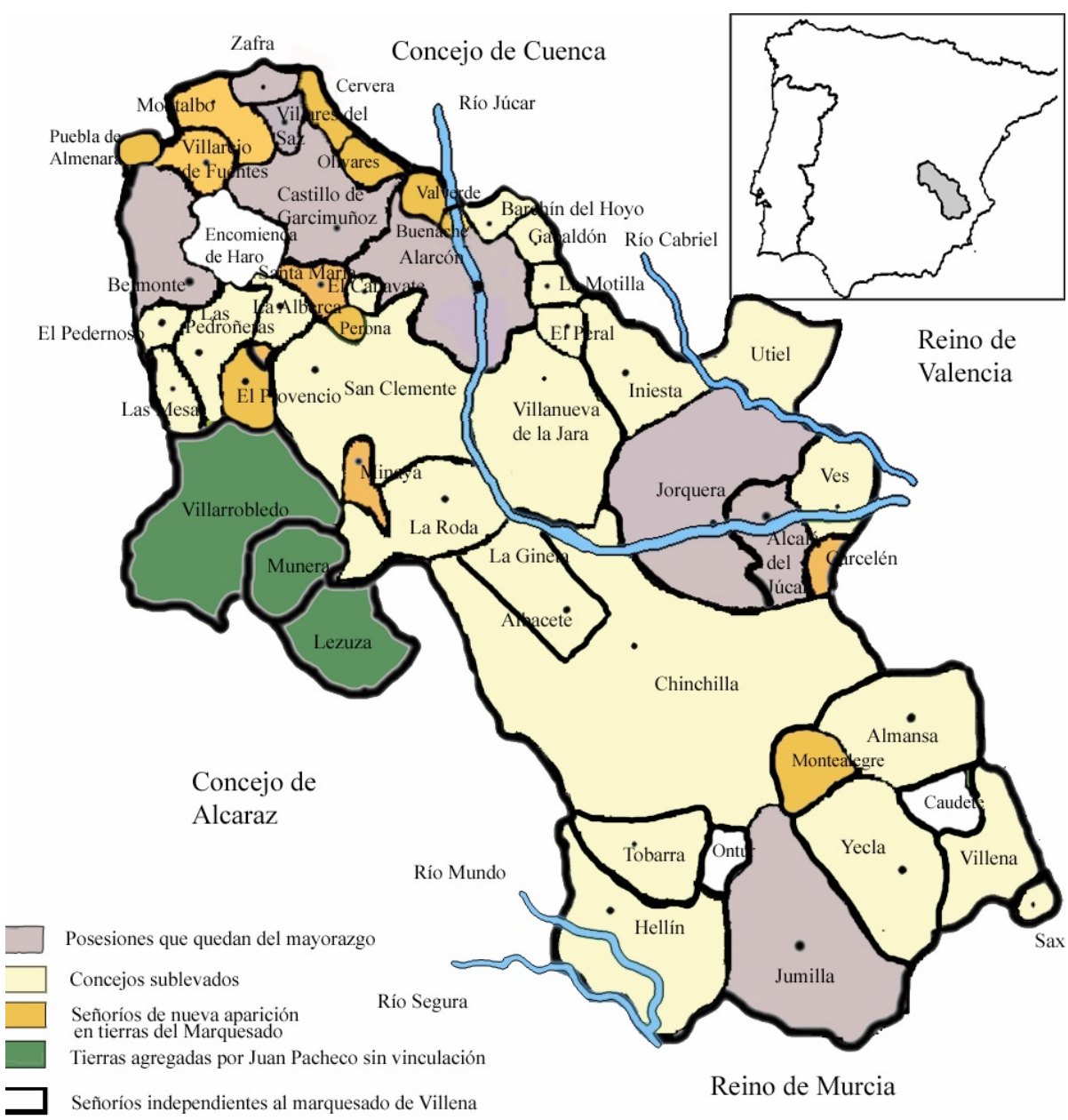

Mapa 2. Marquesado de Villena, 1480. Fte.: Ortuño, 2003, apéndice gráfico.

Cortesía del autor. 
Además, el equilibrio económico fue desigual, de modo que las aldeas de zonas llanas, como Casas Ibáñez, Mahora y Villamalea o Casas de Ves, crecieron más que las villas que eran cabecera de municipio (Jorquera y Ves) situadas en zona montañosa, por lo que fueron arrebatándoles funciones y servicios (tercias, pósitos), o consiguieron privilegios efectivos, como por otra parte sucedió en todo el Reino de Murcia.

Pues bien, la archivística (Cruz, 1997) y la heurística (García Villada, 1921, p. 57. Duranti, 1996) pueden contribuir a aclarar estos procesos históricos, que es lo que se pretende y a lo que a continuación se procede.

\section{CRECIMIENTO DEL PODER REAL Y DE FUENTES ARCHIVÍSTICAS}

El poder real de Carlos I creció con la derrota de las Comunidades (1521), lo que implicó la consolidación del régimen de consejos, la implantación de corregidores y la creación de archivos, como el Archivo General de Simancas (Rodríguez de Diego, 2007), o en el Reino de Murcia los de la Catedral de Murcia (García, 2014) y del Notariado, éstos en los archivos históricos provinciales de Albacete y Murcia. De estos tres últimos son las fuentes documentales que he manejado. La metodología es heurística (búsqueda e investigación de fuentes históricas) y archivística (López, 1998), o la identificación de fondos y sus productores, es decir, de su contexto de producción.

La consolidación del Archivo Real de Simancas (llamado general), con la gestión de los documentos del real patrimonio y los registros de la cámara y los consejos, y la implantación de los registros de actas y contables del cabildo catedralicio mencionado y los de los escribanos permiten contrastar las diferencias entre las élites de poder, el clero y el pueblo común en torno a la autoridad de unos y otros y a la gestión del diezmo.

El estado de Jorquera -Jorquera y sus 13 aldeas, Alcalá del Júcar (Almendros, 1989, p. 25 y 50-59) y Jumilla-, quedó dentro del marquesado de Villena en 1480, al final de la Guerra de Sucesión 
Castellana, del que se separaron mucho antes la Villa de Ves (1272) (en la guerra nobiliaria contra Alfonso X el Sabio) y Carcelén (1398) (Cano, 1984 y 1991). En 1686 se separó además el señorío de Villatoya (Almendros, 2002). Vemos así cómo los conflictos civiles fueron origen de estas segregaciones.

Lo más conocido en esta zona para el siglo XVII es la consecución por el marqués de Villena del privilegio de nombrar alcaldes del concejo de Jorquera en 1636 (Almendros, 1987), pero no lo es tanto que tuvo diferencias con la Diócesis de Cartagena sobre el diezmo, como las tuvieron los señores del Valle del Vinalopó con el mismo cabildo.

La documentación del archivo catedralicio transmite la comunicación entre el personal eclesiástico de las parroquias del marquesado de Villena y el deán y cabildo de Murcia, pero incluye a cosecheros y ganaderos y circunstancias de su vecindad, residencia y condición social, o de problemas con los señores que tenían diezmos.

En el caso de actas y registros notariales su valor informativo alcanzó a circunstancias de trabajo, negocios y propiedad. Además, las actas notariales refieren relaciones eclesiásticas, como poderes de presbíteros para resolver litigios eclesiásticos.

En los años 1574-1578 los ejércitos y armadas de Felipe II sufrieron retrocesos en Túnez y Flandes, y de resultas del esfuerzo económico se llegó a una bancarrota. La documentación decimal más antigua de esta zona se remonta a 1575-1588, en que coincide con dichas circunstancias y con documentos del Archivo General de Simancas ${ }^{2}$, o las Relaciones Topográficas de 1575-1579, aunque la primera documentación seriada es de 1613-1614: cuentas de producción agraria en época de la expulsión de los moriscos mudéjares del Reino de Murcia (los moriscos granadinos del reino fueron ex-

\footnotetext{
${ }^{2}$ Como una pesquisa de un pleito de 1574 sobre parcialidades y bandos en la villa de Jorquera: Archivo General de Simancas (AGS), Consejo Real de Castilla, 592/1. Sobre esta documentación: Aguirre, 1996. Muy distinta a la reseñada por Romero, 1981.
} 
pulsados en 1610), entre ellos 350 de Hellín y de Chinchilla y Tobarra moriscos granadinos (Pascual, 2018, p. 81, 498 y 500). La crisis económica recrudeció en torno a esta expulsión (había antecedido una bancarrota en 1607) y la situación empeoró en 1630-1650 y 1657-1658 (Guerra de los Treinta Años), en que la documentación decimal se diversificó y extendió a la del subsidio y excusado eclesiástico o aportación del clero para los gastos de las Galeras de España, en plena Guerra de Cromwell y final de la Hispano-francesa. De aquí que se vendieran señoríos y corregimientos, como los de Lorca, Hellín y Villena (ver mapa 3).

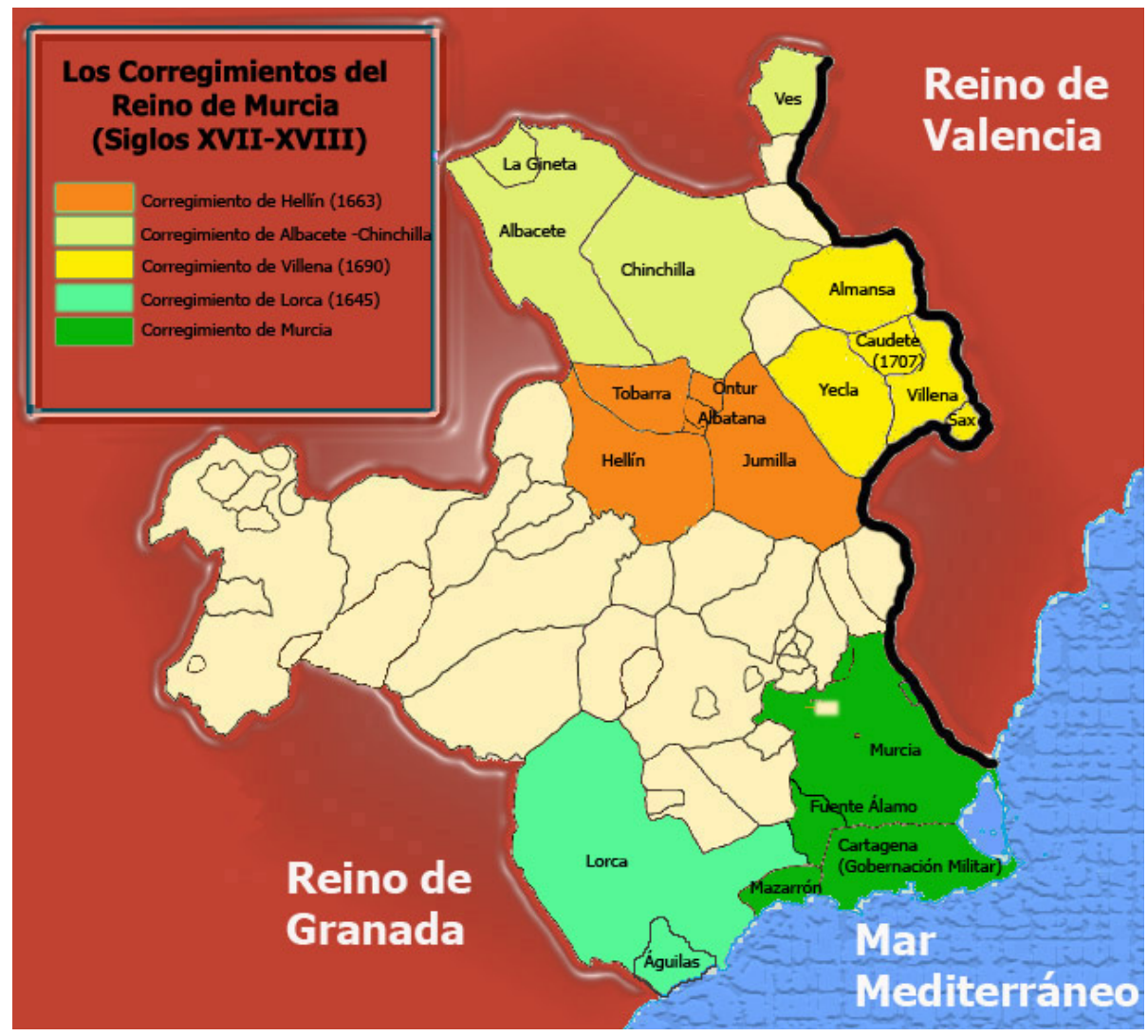

Mapa 3. Corregimientos del Reino de Murcia. Fte.: Muñoz, 2003. Cortesía del autor. 
Otro gran cambio fue el borbónico al que siguió el crecimiento de mitad del XVIII, que se mostró en documentos más numerosos y variados: cartas, certificaciones de producción, expedientes administrativos y judiciales, provisiones de curatos y otros oficios.

\section{ACTUACIONES DE VECINOS DE JORQUERA EN MURCIA Y CARTAGENA}

El crecimiento del poder regio implicó un disciplinamiento y unas encuestas sobre la capacidad fiscal de la población, plasmada en averiguaciones fiscales (del servicio de Cortes, de alcabalas) y relaciones, para aumentar los servicios fiscales. Alcabalas y sisas gravaron compraventas y transacciones mercantiles, el diezmo la producción agraria.

A diferencia de las respuestas de los concejos a las averiguaciones, que tendieron a enmascarar la economía, las actas notariales aportan testimonios muy antiguos de la vida económica del marquesado de Villena, pues los registros o protocolos notariales de Murcia empiezan en 1450, los de Caravaca de la Cruz en 1520, los de Moratalla en 1549 o los de Cartagena en 1558, y ello a pesar de que estos protocolos notariales no son los de las villas de Jorquera y Ves y de sus lugares, como Mahora, por lo que su información es indirecta y fragmentaria ${ }^{3}$.

La implantación de los registros notariales fue mandada por los Reyes Católicos (Pragmática de los escribanos, 1503), a la que Carlos I añadió el registro de censos o rentas, pero estas medidas tardaron en consolidarse, como muestra la amplitud cronológica de los protocolos de Murcia, que nos ofrecen documentos de la primera mitad del XVI y décadas posteriores, como ventas de tierras ${ }^{4}$; ventas

\footnotetext{
${ }^{3}$ Aunque los privilegios conservados en el Archivo Catedralicio de Murcia se retrotraen a los siglos XIII (Torres, 1953) y XIV, no ofrecen tanta información como las actas notariales, salvo excepciones y en un archivo de sus fondos documentales se aprecia sobre todo la continuidad de sus series.

${ }^{4}$ Aparicio Fernández, vecino de Murcia, a Pedro Gasque, de Jumilla, un majuelo en la huerta de Jumilla, junto a la Acequia de las Longueras del campo y otras viñas, por 27.500 maravedíes: Archivo Histórico Provincial de Murcia (AHPM), Notariado (Not.) 284/400 (caja/folio), 16.12.1525. Montojo, 2007.
} 
de cáñamo procedente de esta zona, préstamos y reclamaciones de herencias ${ }^{5}$. Estos registros a su vez se complementaron con los de la Cancillería regia, Cámara y Consejo de Castilla, o Registro General del Sello (Álvarez-Coca, 2010).

Un ejemplo de gran fuente de documentación fue la actividad del beneficiado de Jorquera el doctor Juan Andrés de la Calle, del que luego se trata más por extenso ${ }^{6}$.

El crecimiento demográfico del XVI se manifestó en la aparición de documentos referidos a Cenizate ${ }^{7}$ y -más tarde- Las Navas ${ }^{8}$, aldeas de Jorquera, que muestran a ésta como una villa con numerosas aldeas (13). En ellas se formaron heredades o haciendas, de las que algunas fueron vinculadas en mayorazgos. No es un ejemplo aislado, pues en las décadas centrales del XVI encontramos otros ejemplos parecidos de constituciones de mayorazgos, como el de Agramón de los Valcárcel (Molina, 1996), a consecuencia de ventas de cargos municipales, villazgos y señoríos (Molina/Ortuño, 2009).

\footnotetext{
${ }^{5}$ Aparicio Fernández y Juan Ramón, de Jumilla, se obligaron a entregar a Gómez de Balboa, de Murcia, y Martín de Cutanda, vecino de Mahora, estante en Murcia, 12 millares de esparto verde (o cáñamo) a Luís Gómez, mercader vecino de Murcia, en Cartagena, en 15 días a 6 reales uno, quien a su vez apoderó, junto con su mujer Francisca Navarro, a Alonso Cañavera, vecino de Mahora, para cobrar deudas en ella y otros lugares: AHPM, Not. 284/178, 24.10.1524. Jumilla era una de las villas del estado de Jorquera.

${ }^{6}$ Contrató a un lugareño de Casas Ibáñez para trabajar a medias su heredad del Campillo, en la huerta de Murcia, pero gestionó además intereses materiales en Jorquera y sus aldeas, como rentas que cobró y pagó: AHPM, Not. Funes 1225, año 1630.

${ }^{7}$ Domingo López, vecino de Murcia, apoderó a Martín Martínez, vecino de Jorquera, morador en las Navas, para tomar posesión en su nombre de una heredad o hacienda en Cenizate, aldea de Jorquera, y cobrar la renta correspondiente al labrador que la estaba cultivando: AHPM, Not. 32/83 y 285-6, 11.4 y 10.5.1540. ${ }^{8}$ ACM, Actas 1675-1678, 20.9.1678/179.
} 


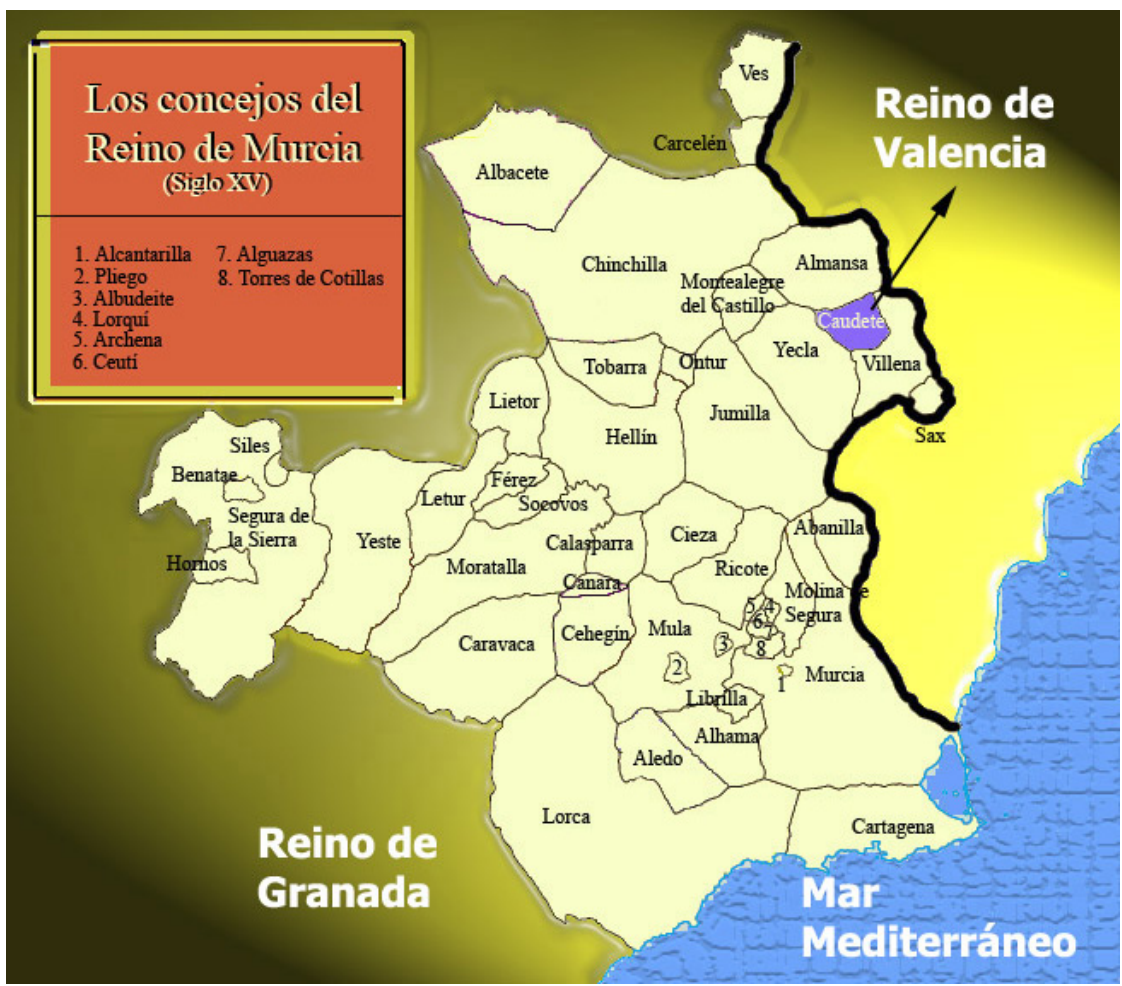

Mapa 4. Concejos del Reino de Murcia s. XV. Fte.: Muñoz, 2003. Cortesía del autor. Como se puede observar Alcalá del Júcar y Jorquera se hallaban a la izquierda del de Ves.

Se dieron tanto muestras de movilidad de la propiedad"; como de su inmovilización ${ }^{10}$. La profesión religiosa de un hijo condi-

${ }^{9}$ D a María Núñez, viuda de D. Francisco de Cantos, apoderó a D. Pedro Núñez García, su sobrino, cura de Corral Rubio y Bonete, para vender unas tierras y viñas del lugar de Cenizate: Archivo Histórico Provincial de Albacete (AHPAl), Notariado (Not.) 1.848/21, 7.11.1698. Sobre el archivo: Pascual, 2002.

${ }^{10} \mathrm{D}^{\mathrm{a}}$ Catalina Cortés Pardo de la Casta, mujer de D. Juan Soriano Cano Manuel, regidor perpetuo de Chinchilla, ella natural de Mahora (Jorquera), declaró que fue obligada a los 14 o 15 años por su tío y tutor Julián Cortés Pardo a hipotecar los bienes de su hijuela hereditaria en un censo a favor de la capellanía que fundó D. Juan de Manurga, y ella se negó a dejar o reconocer, pues lo hizo por temor reverencial, aunque defendió el derecho de sus hijos a heredar dicha capellanía y otra en la parroquia de Villanueva de la Jara; o Pedro Cerdán Barbarán, vecino de la Alberca, y consortes, de Mazarrón, entre ellos su madre, María Barbarán, vecina de Jorquera, vendió tierra a Juan Ruiz Melgares, vecino de Mazarrón, por poder en Jorquera a 23.4.1765 de Tomás Valero y Pascual Gómez, Antonia y Josefa Celdrán, esposas: AHPAl, Not. 1.848/2-5, 9.2.1699; AHPM, Not. 11704/32, Mazarrón, 4.5.1765. 
cionó por ejemplo el reparto de la propiedad ${ }^{11}$, pero también la explotación de la tierra en otras comarcas, como Chinchilla atrajo a vecinos de Jorquera, colindante con ella ${ }^{12}$.

Por otra parte, como muestra de actividad, algunas tiendas de mercaderes de Cartagena atrajeron clientes de villas del estado de Jorquera ${ }^{13}$; o las de Murcia a vecinos de Jorquera y Villamalea ${ }^{14}$, o mercaderes de tránsito por Mazarrón, como un vecino de Huéscar, territorio de genoveses del Reino de Granada (Andújar, 1999 y 2005; Girón, 2005 y 2012) ${ }^{15}$, lo que indica una movilidad mercantil para llenar un hueco o necesidad de consumo en el estado de Jorquera o la tierra de Ves.

\section{CRISIS Y RECUPERACIÓN A TRAVÉS DE LA DOCUMENTACIÓN DECIMAL ECLESIÁSTICA: ESTADO DE JORQUERA}

La crisis demográfica y económica de gran parte del XVII y principios del XVIII, en la que me voy a centrar ahora, se manifestó claramente en los diezmos del señorío de Jorquera, que proporcionaron ingresos o rentas a los canónigos o capitulares de la Catedral de Murcia, quienes tuvieron intereses económicos sobre ellas ${ }^{16}$,

\footnotetext{
${ }^{11}$ Un ejemplo posterior: D. Andrés Clemente de Aróstegui, vecino de Jorquera y morador en Valdeganga, donó unos cebadales de la herencia de su mujer a su hija $\mathrm{D}^{\mathbf{a}}$ María de San Andrés, novicia del Convento de Santa Ana, quien había renunciado a ella: AHPAl, Not.1.848/278, 25.5.1711.

${ }^{12}$ Pedro Fernández, de Pozo Lorente, contrató a medias de José Ruiz Amoraga el heredamiento de Orán con 6 pares de bueyes, por 4 años, con las fanegas de pan como pares: AHPAl,Not.1.848/269,20.11.1710.

${ }^{13} 0$ cerca como Minaya: un vecino Juan de Caravaca se obligó a pagar 5 ducados y 70 reales a Bartolomé García y Domingo Pérez, tabernero, por préstamo: AHPM, Not. 5.159/172, 186v, 14, 22.9.1559.

${ }^{14}$ Antón Serrano se obligó a pagar a Felipe Díaz Pardo 370 reales por 12 arrobas de acero y Martín de Alarcón 240 y 189 reales por 2 quintales y una partida: AHPM, Not. 710/197, 7.5.1641, 709/186 y 203, 12.4 y 25.5.1641.

${ }^{15}$ Como Salvador de Buitrago con respecto a Manuel Real, de Jorquera, por un préstamo: AHPM, Not. Martínez, 6.741/2v, 6.1.1605.

${ }^{16}$ ACM, Libro 12 Ac.Cap. 1616-1621, f. 27, 25.10.1616.
} 
además de al marqués de Villena ${ }^{17}$ y al rey como principales perceptores, confluencia de intereses que dio lugar a conflictos en torno al reparto de los diezmos, o a investigaciones sobre sus rendimientos. Una primera aproximación al diezmo eclesiástico del estado de Jorquera la ofrecen las relaciones del diezmo de 1589-1591 conservadas en el Archivo General de Simancas, sección Patronato Eclesiástico (legajo 135), aunque con referencia a todo el Arciprestazgo de Jorquera, sin diferenciar sus villas y aldeas, pues es un documento general a la Diócesis de Cartagena. Podríamos compararlo a las averiguaciones de alcabalas de 1588-1591 en cuanto indica un esfuerzo informativo importante, como el de las relaciones topográficas y otras averiguaciones fiscales (servicios de cortes). Estas relaciones del diezmo muestran recolecciones de cereales (trigo, cebada, centeno y avena), vino, miel y cera, menos variadas que las de Almansa, Sax y Yecla, en que se cosecharon además ajos, cebollas, guijas, alcandía, maíz y mijo, y menos cuantiosas que las de Chinchilla y Albacete-Gineta.

La posición geográfica del estado de Jorquera en el norte del Reino de Murcia y marginal en el corregimiento de Chinchilla, por razón del relieve fluvial y montañoso, no impidió un determinado tráfico a través de los puertos serranos de Ayora y Almansa, por los que se ha detectado hubo contrabando de seda (Muñoz, 2015, p. 237). Pero voy a centrarme en la producción agrícola a través del diezmo eclesiástico, por medio de la documentación del cabildo catedralicio de Murcia. Es verdad que hay otras fuentes que dan a conocer los rendimientos del diezmo, como las relaciones del valor de los diezmos del Obispado de Cartagena de 1589-1591 ${ }^{18}$, o las respuestas del Catastro del Marqués de la Ensenada (Sánchez, 2010 para Chinchilla).

\footnotetext{
${ }^{17}$ Archivo Histórico Nobleza (AHNob), Frías, 726/1-23, 1526-1691: Documentos de la recaudación de los diezmos y tercias reales en el estado de Jorquera. Sobre el archivo: Gómez, 2007. Lafuente, 2000.

${ }^{18}$ AGS, Patronato Eclesiástico, legajo 135. Ver: Fuente, 1995. Hay otra en el AHNob.
} 
En 1616 algunas iglesias del estado de Jorquera amenazaron ruina, por lo que se tendió a abandonarlas y a trasladar el culto a ermitas, y de aquí que el cabildo reclamó su reparación al marqués de Villena. Pero los concejos de la zona requirieron el cereal de las tercias (o silos), a lo que accedió el cabildo, aunque previa consulta al archivo y con condiciones. Recurro a esta fecha como punto de partida pues por entonces se aprecia la mayor incidencia de las dificultades con el marqués de Villena (y duque de Escalona), señor del estado de Jorquera ${ }^{19}$.

Se denunciaron al cabildo excesos en la gestión de las tercias, en 1617, como estaba sucediendo en otros ámbitos por la corrupción, extendida en la corte ${ }^{20}$, por lo que el canónigo encargado de la relación del cabildo con el estado de Jorquera envió un visitador a examinarlas y reformarlas ${ }^{21}$, pues las tercias formaban una red de percepción del diezmo, fueran eclesiásticas, reales o señoriales, precisada de control.

Pero el problema se alargó y complicó en 1618, en que intervino el Arzobispado de Toledo, superior jurisdiccional del marqués de Villena ${ }^{22}$, pues éste dio orden al corregidor de Jorquera de que nombrara visitador para que remediara los abusos de los fieles de tercias $^{23}$, que era frecuentes.

De 1620 es la primera cuenta de tazmía (relación en que se anotaban los granos recogidos en la tercia) del estado de Jorquera que se conserva en el archivo catedralicio, dando razón de los frutos, al tiempo que proseguía el pleito y en plena coincidencia con las actuaciones anticorrupción de la Junta de Reformación en la corte.

\footnotetext{
${ }^{19}$ ACM, Libro 12 Actas Capitulares 1616-1621, f. 7, 2.9.1616.

${ }^{20}$ ACM, Libro 12 Ac.Cap. 1616-1621, fs. 88, 90, 95 y 108v, 20 y 30.6, 18.7 y 1.9.1617.

${ }^{21}$ ACM, Libro 12 Ac.Cap. 1616-1621, f. 127v, 3.11.1617. Sobre el marqués: Molina/ Ortuño, 2009.

${ }^{22}$ ACM, Ac.Cap. 1616-1621,f. 37, 27.9.1618. El Arzobispado de Toledo fue superior del de Cartagena.

${ }^{23}$ Ídem, 257, 4.1.1619. Ver: AHNob., Frías, 724/59, 1619-, complementario del anterior.
} 
La proporción de fanegas obispo/cabildo fue la que se dio entre el total recolectado y lo que le tocó a cada uno, cuenta que respalda lo dicho por el Diccionario Geográfico-histórico de Miñano ${ }^{24}$ sobre el predominio de los cereales en Jorquera.

Las cuentas del diezmo estiman los rendimientos del estado de Jorquera desde 1620, pero de forma interrumpida. Por entonces, al inicio de la época del conde duque de Olivares como valido (16211643) de Felipe IV, se sufrió en el reino de Murcia una fuerte crisis demográfica (de la que dan testimonio los recuentos de 1631 o de la sal y 1646 o de los juros) y económica, esta última a causa de un periodo de malas cosechas o crisis de subsistencias y de fuertes contribuciones fiscales y militares, como se puede comprobar a través de la contabilidad de rentas de alcabalas, millones (o servicios de millones), o servicios ordinarios y extraordinarios de cortes (Ruiz, 1994).

Villamalea fue la aldea más poblada de Jorquera y con concejo electivo, sede de industria textil al inicio del XVII (Sánchez/ Cano, 1989), y Mahora fue la segunda aldea más poblada ${ }^{25}$ y con concejo electivo, y son documentadas desde 1642, en plena crisis de la monarquía, tras las rebeliones de Cataluña y Portugal, pues las tropas realistas españolas fracasaron en la batalla de Lérida de ese año contra las catalanas y francesas. Se había reiniciado en 1627 un ciclo de crisis económica que culminó en 1648-1652, con la gran epidemia de peste y las bancarrotas de 1647 y 1652, por lo que en 1642 se estaba en mitad del ciclo de pandemia y crisis (Ruiz, 1994). Villamalea fue incluida en la contabilidad a veces con Carcelén, señorío aparte ${ }^{26}$.

\footnotetext{
${ }^{24}$ «el río corre por un cauce profundísimo, y en sus dos orillas hay huertas bien cultivadas cuyos principales productos son trigo, cáñamo y árboles frutales [...]. Lo demás del terreno es secano y produce cebada, avena, centeno, poco vino y azafrán»: Miñano, 1827, t. 5, p. 108. Ver: Almendros, 2009.

${ }^{25}$ «situado en terreno llano y feraz produce granos vino y azafrán»: Miñano, 1827, t. 5, p. 361 .

${ }^{26} 11.038$ y 1.750 reales; 59.508 maravedíes al estado de Jorquera: Cuentas del subsidio por Lucas Carcelén: ACM, 617/27, año 1636. De vino se obtuvieron 126 @ a 5 reales en Villamalea (donde se apedreó o hubo pedrisco), 247 @ a 4 en
} 
La producción dio en Jorquera, según las cuentas de tazmías de 1642 y 1645: trigo, cebada, centeno, avena, panizo (cinco cereales), lana, ovejas y cabras, como en Casas Ibáñez, pero en Fuentealbilla también gallinas, hortalizas y vino; en Cenizate cera, queso y hortalizas; en Alatoz cera, miel, queso, guijas, garbanzos y gallinas, además de cereales y lana. La cera y miel se extendió entonces a partir de la apicultura (Lemeunier, 2011). El azafrán surgió más tarde, en $1675^{27}$, dándose por lo tanto una diversificación.

El diezmo fue administrado primero en 4 tercias (Jorquera, Villamalea, Mahora y Cenizate) del marqués de Villena, por razón de una concordia con el obispado, que le obligó a mantenerlas a cambio de cobrar el rediezmo y dedicarlo a obras de iglesias, y en aquéllas hubo dos fieles en cada una (uno del marqués y otro del cabildo), pero el marqués aumentó las tercias a ocho, al añadir las de Casas Ibáñez, Fuentealbilla, Alatoz y Carcelén, en las que sólo hubo fiel del marqués y de las que a la última se acusó de estar fuera de la dezmería ${ }^{28}$. Pero se denunciaron además otros abusos ${ }^{29}$.

Se acumuló una deuda de 400 fanegas de cereales de la tercia de Mahora sólo de 1625, o 150 de 1630, más 118 de Cenizate, por lo que se propuso poner un fiel eclesiástico en esta última, puesto que el marqués les cobró terrazgos, de los que ellos argüían estar exentos, en una clara oposición anti-señorial.

\footnotetext{
Mahora,63@a 4 en Cenizate, $60 @ 6$ azumbres a 4 en Navas y $11 @ 2$ azumbres en Golosalvo: ACM, 508.

27 «Diezmo de azafrán. El señor maestre escuela dio razón al cabildo como ha tenido noticias por medio de algunas personas que en el estado de Jorquera se coge cosecha de azafrán considerable y que no se cobra diezmo de ello que vea el cabildo lo que en esto se ha de hacer porque le parece materia reparable; y el cabildo habiendo oído al dicho señor maestre escuela y conferido acordó de cometerlo y lo cometió a los señores maestre escuela y doctoral para que se procuren informar bien de lo que es esto y pongan todo el cuidado para que se cobre el diezmo de el azafrán»: ACM, Actas 1675, 358v, 26.11.1675 y 21.4.1676.

${ }^{28}$ ACM, 363/57 Memorial 1631.

${ }^{29}$ ACM, Ac.Cap. 1622-1626/81v y 129, 7.2 y 13.10.1623.
} 
Surgió así un pleito con los labradores de Cenizate ${ }^{30}$ y Mahora, pues encubrían sus cosechas para que no se conocieran ni controlaran, lo que se justificó ${ }^{31}$. Los abusos denunciados fueron tales como no dar cuenta en el medio diezmo de los ganados, amparándose en el corregidor, letrados y criados $^{32}$. Pero hay que tomar con gran precaución estas descalificaciones pues no conocemos la defensa.

En Villamalea fue fiel el licenciado Diego Ortiz Pardo, marido de $\mathrm{D}^{\mathrm{a}}$ Jusepa Catalina Velasco, que escribió a Gregorio de Monteagudo (6.12.1620) informándole del retraso en enviar la tazmía por las dilaciones de los arrieros y de la quietud de los precios del cereal (12-13 reales trigo), sujetos a la tasa los de cebada y centeno, pues el marqués de Villena y D. Antonio de Verástegui los daban al fiado, y los pósitos lo prestaban a labradores, medidas que permitían afrontar la crisis y sus dificultades.

Casas Ibáñez protagonizó entonces la fundación de la Cofradía de San Agustín (Almendros, 2018), lo que permite intuir una cierta aglutinación de los lugareños de una aldea que como otras podían crecer más que Jorquera, su cabeza, por su mejor posición.

El cabildo catedralicio supo de fraudes en la recolección del trigo, cereal mayoritario, pues se ocultó en cuevas y caminos ${ }^{33}$. Las tercias se deterioraron y hubo otros menoscabos, pues diezmaban en mosto en vez de $u^{3}{ }^{34}$, y los hubo de la lana desechada por los

\footnotetext{
${ }^{30}$ Fueron deudores Pedro Montero, Juan Martínez Cabronero, Antón Martínez, Martín Gómez, Gabriel Martínez, Juan Simarro, Juan Jiménez mozo, Antonio Navarro, Martín Gabaldón, Francisco García Real, Julián López Herrero, Benito Martínez, Francisco Roldán, Asensio García, Martín García, Juan García, Alonso Mañes, Francisco de la Plaza Hinojosa, Benito Pardo, Bartolomé González el mozo, de Cenizate. En ella se obtuvieron 55 arrobas de lana, de las que tocó al cabildo 12 arrobas, 9 libras y 6 onzas (Isidro Monedero y Mateo García, 1620).

${ }^{31}$ ACM, 363/57. Este documento acompaña al memorial del Doctor Juan Andrés de la Calle, enviado al Dr. Vélez y remitido al provisor del obispado, y pienso que lo hace por el pleito.

${ }^{32}$ Memorial de 1631: ACM, 367/57.

${ }^{33}$ Memorial de 1631: ACM, 367/57.

${ }^{34}$ Memorial de 1631: ACM, 367/57.
} 
mercaderes de Cuenca que la compraban ${ }^{35}$. Se desplazó ganado a otros términos o el ganadero se avecindó en otras villas ${ }^{36}$, pretendiendo aligerar el peso de una contribución muy gravosa, con incidencia en la crisis general ${ }^{37}$. Incluso se llegó a acusar de mudar viñas por melocotoneros para no pagar diezmo, por no estar estos últimos recogidos entre los productos gravados ${ }^{38}$.

Alcalá del Río Júcar fue villa del estado de Jorquera, con 90 vecinos en 1579; pues 300 se mudaron a aldeas de Jorquera (Fuentealbilla, Casas Ibáñez, Alborea, Serradiel, Marimínguez, Alatoz y Pozo Lorente), con las que tuvo comunidad de término, y contribuyó por Cuenca, pero fue señorío del marqués de Villena, como Jorquera y Jumilla ${ }^{39}$. Respecto a Alcalá del Júcar según la relación topográfica de 1579 produjo melocotones, albaricoques y membrillos ${ }^{40}$.

\section{SUBSIDIO Y EXCUSADO EN EL ESTADO DE JORQUERA}

A partir de 1660 se inició una lenta recuperación demográfica y económica. Predominaron entonces las cuentas del subsidio y excusado, una de las tres gracias o mercedes pontificias eclesiásticas concedidas al rey de España para sostener la escuadra de galeras.

En 1662 se hicieron tazmías de vino separadas ${ }^{41}$. Estas cuentas permiten conocer que gravaron a laicos, generalmente propie-

\footnotetext{
${ }^{35}$ Sobre Jorge Enríquez y otros comerciantes de Madrid y Cuenca que compraron esta lana: Belinchón, 2001, p. 1027. Diago, 2013, p. 384-385 y 393-395. Lo confirma el memorial de 1631: ACM, 367/57.

${ }^{36}$ ACM, 706/3.

${ }^{37}$ Mucho antes Felipe II ordenó al marqués de Villena que no llevase impuesto de montazgo a los ganaderos de la Mesta que lo hubiesen pagado en Chinchilla: Ejecutoria 6.5.1580: AHNob, Frías, 725/21.

${ }^{38}$ Memorial de 1631, ACM, 367/57. Para finales del XVII: Lemeunier, 1987, p. 8.

${ }^{39}$ En Jumilla se denunció abusos: ACM, AC 1616/284, 443, 446, 22 y 25.6, 9.7.1619; 1622-1626/130v y 134, 20.10 y 10.11.1623 Figura con 646 vecinos en 1631. ${ }^{40}$ ACM, Ac.Cap. 1622-1626/108, 118 y 124, 30.5, 8.8 y 19.9.1623. ACM, 706/3, fs. 13 у 30.

${ }^{41}$ En Mahora dio 6 arrobas y 2 azumbres a 8 reales (50 reales), en Alborea 8 a 6'5 (52), según Bartolomé Gómez Fernández: Casas Ibáñez, 16.7.1663: ACM, 597/15.
} 
tarios y por lo tanto aproximarnos a las élites ${ }^{42}$, y las del expolio y vacante (rentas del obispo durante época de su vacante) dan a conocer los productos ${ }^{43}$.

Tal diversidad de productos se confirma al observar la propiedad $^{44}$.

${ }^{42}$ El recolector del subsidio y excusado tomó cuentas en Villamalea (11.8.1665 y 28.8.1667) a Francisco Ortiz de Espinosa, subcolector del estado de Jorquera, que dio cargo de: 206.364 y 240.798 maravedíes de repartimiento al arciprestazgo, 10.318 y 12.035 de premio, 184.753 y 207.898 de repartimiento de excusado, 9.238 y 10.395 de su premio, total 410.673 y 574.308 y data de 55.101 y 76.885 de no haber cobrado la $1 / 2$ del beneficio del cura de Jorquera, 81.708 y 114.024 de $1 / 2$ de reparto a las rentas del duque de Escalona y marqués de Villena, 10.524 y 14.687 de $1 / 2$ de beneficio al cura de Alcalá, 16.794 del beneficio y capellanía de Ves (1667), 997 de premio de la plata a la iglesia de Fuentealbilla, 158 a la capellanía de San Juan de Casas Ibáñez, 233 a la de Alcalá, 449 y 738 a la Abadía de San Benito, 50 a la capellanía de Juan Pérez y Juana Gómez en Alborea, 7.480 y 7.480 de salario y 680 y 680 de costes de realización. Gastos: 10.633. Cuentas de excusado de 1665 y 1667, ACM, 527/2 y 526/7.

${ }^{43}$ Dio 467'04 fanegas de trigo, 268'05 cebada, 202'03 centeno, 52 avena, 12 libras, 2 arrobas y 1 azumbre de azafrán, 16'12 libras de miel y 6.238'12 reales de rentas: 1.700 de 200 fan. cebada, 525 de 38'02 de avena, 5'17 de 0'5 de panizo, 29'9 de 2'11 de adeya, de 101 cabezas de ganado lanar y cabrío (105 de 5 en Alborea a 20, 152'21 de 9 en Alcalá a 16, 234 de 16 en Ves a 14, 84 de 6 en Alatoz a 14, 1.088 de 64 en Fuentealbillla, Villamalea y Cenizate, Mahora a 17), 1.664'04, 425'20 de 15 arrobas lana a 28,11'03 de 2 libras y 7'50 arrobas de cera, 1.047 de 261 arrobas 6 azumbres de vino a 4, 676'16 de minucias y 1'17 de 1'50 libras de queso a 1 real: Cuentas del expolio de 1695: ACM, 696/7. Sale de nuevo el azafrán.

${ }^{44}$ En la aportación al matrimonio de D ${ }^{a}$ Catalina Cortés Pardo de la Casta, mujer de D. Juan Soriano Cano Manuel, regidor perpetuo de Chinchilla, ella natural de Mahora (Jorquera) 32.000 reales en ganados (600 cabezas consumidas), 4.000 en muebles y 4.000 en joyas, una casa, viña y cebadales en Mahora, la primera vendida en 1.880 reales a D. Francisco Villanueva, 15 almudes de cebadales en 1.180 a Aparicio Gómez y quedaron 117 almudes en Golosalvo por 2.000 reales, una viña de 2.600 vides en Mirón y otra de 1.000 vides en 1.000 . Fue hija de Alonso Pardo Cortés y D ${ }^{a}$ Isabel Fernández Monsalve y hermana de Alonso Pardo Cortés, casado a quien cedió indebidamente $1 / 2$ herencia de su tío, y Julián Cortés y cuñada de Diego Cano Manuel, presbíteros, y fray José Cano Manuel, dominico en Chinchilla. AHPAl, Not. 1.848/2-5, 9.2.1699. ver además Simón, 2009, nota 26. 


\section{RECUPERACIÓN: EL ESTADO DE JORQUERA EN EL SIGLO XVIII}

En el siglo XVIII se expandió la gestión económica del cabildo catedralicio de Murcia en el estado de Jorquera a las nuevas parroquias creadas en 1721, dando lugar a una documentación más numerosa, sobre todo contable, que sirve de base a este epígrafe.

Los años 1731-1734, posteriores a la Guerra de Sucesión de España, pero de guerra en Italia (la de Sucesión de Polonia), permiten identificar a algunos miembros de las élites de los territorios de Jorquera y Ves, en concreto de quienes fundaron memorias y obras pías, y a algunos grupos organizados en cofradías, que fueron afectados por el reparto fiscal del subsidio y excusado eclesiástico (tabla 1). Al fundar tales obras y memorias pías hipotecaron algunos bienes, para dar seguridad a la continuidad de los gastos de misas ${ }^{45}, \mathrm{o}$ las cofradías constituyeron rentas, que debían pagar sus herederos. Eran por ello propietarios de casas, tierras y cultivos, y por lo tanto capaces de superar la mera subsistencia, lo cual no significa que fueran oligarcas aunque sí poderosos.

Hay que señalar que en 1716-1720 (años de la Guerra de Navarra) Mahora, Las Navas, Cenizate, Villamalea, Fuentealbilla, Casas Ibáñez, Alatoz y Jorquera añadieron azafrán a cereales, lana, vino y minucias, pero no Golosalvo, Valdeganga, Abengibre, Motilleja y Pozo Lorente, lo que les permitió obtener unos excedentes de destino comercial.

Acabada la Guerra de Sucesión hubo algún crimen y endeudamientos en Jorquera y aldeas de su término ${ }^{46}$, pues en 1709 y

\footnotetext{
${ }^{45}$ El obispo y capitán general Luis Belluga (después cardenal) decretó en 1723 a favor de una petición de José Molero, cura de Cenizate, para que se extendiese la misa del alba fundada en 1712 a todos los días de la semana, dotada con limosnas y renta de un horno que fue donada: ACM, 329/34, 1751: traslado de decreto y diligencias de Francisco Antonio Galiano, 1723 y 3.1.1724. Además consiguió que D. Pedro Núñez Garrido, cura párroco de Chinchilla, obligase las rentas del curato a favor de la congrua de 70 ducados de D. Andrés Núñez Monteagudo, su sobrino, clérigo de menores órdenes de Villamalea: AHPAl, Not. 681/63-66, 1 y 8.7.1719. ${ }^{46}$ Andrés Sánchez Ochando, escribano de Jorquera, requirió los autos de la causa de la muerte de José de Fuentes, vecino de Jorquera, a Feliciano Moreno
} 
1710 se acumularon deudas con vecinos de Chinchilla ${ }^{47}$, y vecinos de Carcelén y Mahora compraron ganado a los de Chinchilla ${ }^{48}$, lo que indica la importancia de la ganadería en el estado de Jorquera y la obtención de dinero de ésta, pero también la posibilidad de redimir censos o quitar hipotecas ${ }^{49}$, pues fue la Guerra de Sucesión un período crítico tras el que hubo una muy lenta recuperación por las continuas guerras hasta la Paz de Aquisgrán de 1748.

Se repartieron subsidio y excusado en 1716 , tras años de no hacerse, por lo que los comisarios de la cruzada revisaron los repartos a partir de 1721 y de aquí que procedieran contra varios vecinos por deudas ${ }^{50}$, en 1722 el Tribunal de Cruzada apremió a alguno ${ }^{51}$. En el inicio de un contexto de recuperación, en 1721 el obispo Belluga dividió el curato de Jorquera en otros trece (Almendros, 2005; Irigoyen, 2005) y creo algunos montepíos frumentarios, como el de Jumilla.

Benítez, regidor perpetuo y teniente de corregidor de Chinchilla, ante quien corrió el proceso, por lo que fue encarcelado el escribano, quien fue acusado de desatención por el teniente de corregidor, quien ganó provisión de los acaldes del crimen de la Real Chancillería de Granada para fulminar autos al escribano: Fianza de Blas García de 500 ducados derivada de real provisión de 23.4.1722: AHPAl, Not. 1.849/23, 8.5.1722.

${ }^{47}$ D. Alonso Pardo de la Casta, lugareño de Mahora, compró 339 cabezas de ganado del diezmo del cabildo de Murcia; José Molina y Francisco Martínez Rosillo, de Chinchilla, apoderaron a Pascual Pérez y Jorge Montoya Guerrero, de Valdeganga y Motilleja (Jorquera), para cobrar deudas; Pardo se obligó a pagar 4.407 reales por Benito Pardo de la Casta, de Murcia: AHPAl, Not. 1848/220, 227, 254, 17.3, 6.8.1709, 8.7.1710.

${ }^{48}$ Sebastián Fons y Juan Gil, de Carcelén y Jorquera, compraron 200 cabras a D. Fernando Núñez de Reina y Balterra, de Chinchilla, por 4.800 rls. para San Miguel: AHPAl, Not. 1848/224, 17.6.1709.

${ }^{49}$ Juan González, vecino de Jorquera y morador de Mahora, suprimió 700 rls. de un censo al Convento de Santa Ana de Chinchilla: AHPAl, Not. 1.848/50, 8.2.1707. ${ }^{50}$ José Luján, vecino de Jorquera, por deuda de 2.185,08 reales de diezmo de 1719 y Andrés García Ponce de 605,25 reales de ganado de Fuente Albilla (1712), José Ochando (517'17 de minucias de 1712) y Martín Torres (163,10 del vino de 1712), de Alcalá del Júcar, y Cristóbal de Torres, de Jorquera, Carcelén y Pozo Lorente: ACM, 362/7 y 365/24.

${ }^{51}$ Se le embargaron huertas de morerales, viñas y parras cercanas a Abengibre: ACM, 362/27, 1722-1723. 


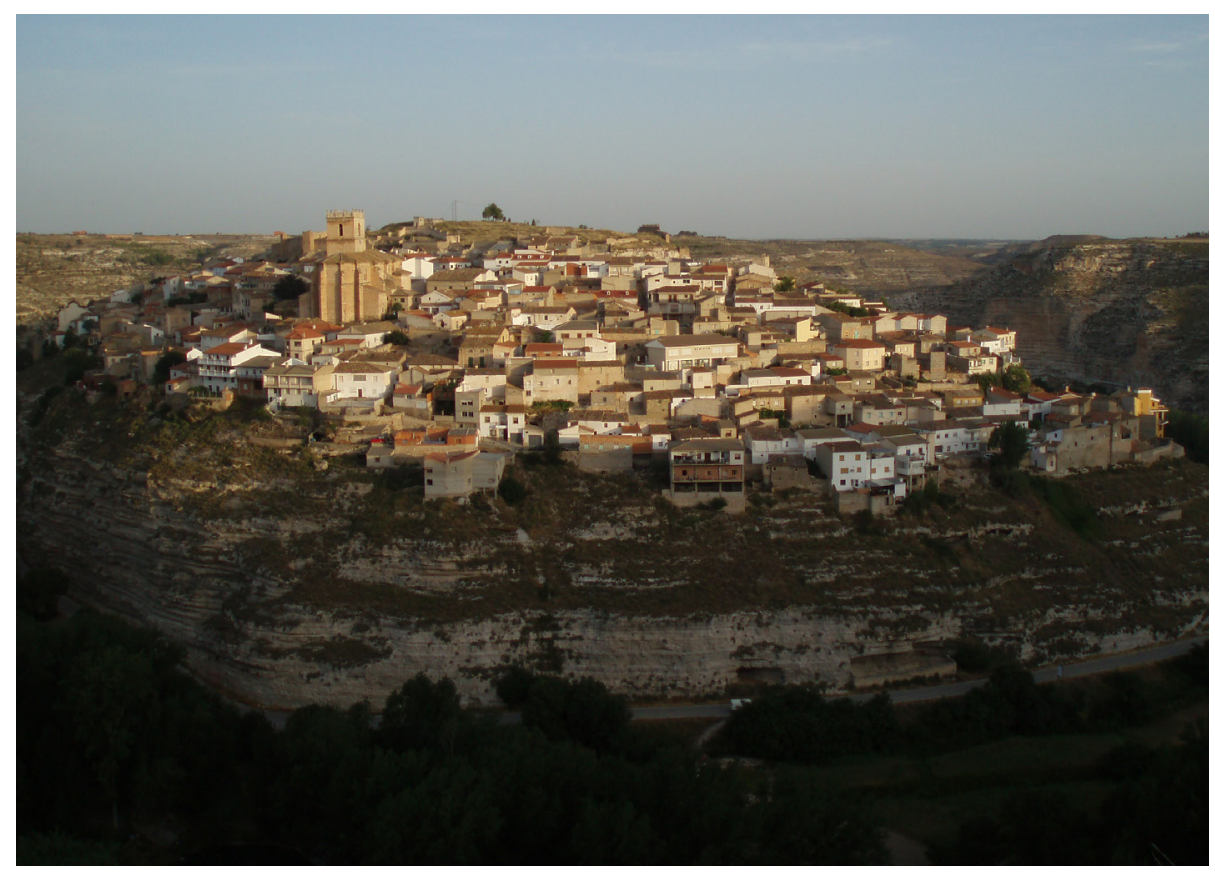

Fig.1 Vista de Jorquera. Fotografía Pedro José Jaén. Cortesía del autor.

Las cantidades de diezmo recogido en 1728 y 1731 de Jorquera y Jumilla por subsidio y excusado son las mismas, lo que indica quizá su gestión por arrendamiento. Por ellas consta que ni Jorquera, Mahora, Villamalea, Cenizate, Fuentealbilla, Casas Ibáñez y Alatoz fueron grandes recolectoras de lanas (divididas en prieta o negra y blanca), a diferencia de Las Navas, que la remitió a veces a Alicante ${ }^{52}$, sede de numerosos comerciantes y cercana por el corredor de Almansa, pero Mahora, Villamalea y Cenizate sí lo fueron de cereales (trigo, cebada, centeno y avena), seguidas de cerca por

\footnotetext{
52 Tomás de Segovia, vecino de Jorquera, morador de Villamalea, se obligó en 30.8.1717, a favor de D. Pedro de Robles Corbalán y Toledo, caballero de Santiago, señor de Villamiel y regidor perpetuo de Toledo, a pagar 11 novillos por 4.050 reales, por lo que entregó lana que llevó con sus carretas a Alicante, a D. Andrés Luís Cheriguini, de que adeudó 1.380. Además Ginés García, vecino de Agost, se obligó por D. Manuel Ferrando Roselló, vecino de Alicante, en 17.850 reales a favor de D. José Ruiz Amoraga, de Chinchilla, por 350 cabras para abasto de carne: AHPAl, Not. 681/6/57-58 y 67, 19.6 y 17.7.1719. Sobre este tráfico: Montojo, 2008.
} 
Fuentealbilla y Casas Ibáñez y de lejos por Jorquera y Alatoz. Mahora, Villamalea. Casas Ibáñez y Cenizate recolectaron mucho más azafrán que las demás poblaciones o tercias, un producto comercial con un gran precio (Almendros, 1989, p. 39-40). La diferencia entre los datos contables de 1715-1720 con los de 1766-1771 permite apreciar un gran aumento.

La dezmería de Jorquera dio origen a pleitos ante el Consejo Real de Castilla con Valdeganga sobre adehesar tierra, o con Casas de Juan Núñez sobre respeto de pastos comunes ${ }^{53}$, muestra de alguna actividad. Alcalá del Júcar formó un partido en 1765, del que dependió Abengibre ${ }^{54}$.

La producción vinícola se intensificó: Casas Ibáñez, Mahora, Villamalea y Fuentealbilla fueron en este orden las que más cosecharon, por encima de 1.500 arrobas, como en Yecla por entonces (Carpena, 2019, p. 26-28). Abengibre y Balsa de Ves construyeron nuevas iglesias en 1734-1740 la primera y 1782 la segunda (Almendros, 1994).

En 1772 los fieles de la tercia de Jorquera certificaron los frutos y rentas de los diezmos de 1767-1771, en que destacaron por su montante geja o jeja (trigo de mala calidad) y trigo candeal, después cebada, centeno y avena, aunque lana y azafrán tuvieron el doble o triple de precio, pero su montante fue mucho menor; y los precios empezaron a bajar en 1769 y siguieron bajando en $1771^{55}$, posiblemente por la liberalización de precios de 1765 que provocó el motín de Esquilache.

La parroquial de Jorquera tuvo unas rentas anuales, entre las que estuvieron algunas procedentes de cofradías, ermitas y capellanías:

\footnotetext{
${ }^{53}$ Archivo Histórico Nacional (AHN), Consejos 31729/7 y 31810/3, 1744-1782 y 1748-1749. Cruz, 1996.

${ }^{54}$ Carta de Diego Malo y Hombrados a los contadores: ACM, 650/13, Abengibre, 16.12.1766.

${ }^{55}$ Informe de Juan Antonio Ortega Urrea y Benito Abellán Ortega, 12.12.1772: ACM, 385/34.
} 
Tabla 1 Cuentas del Subsidio y excusado de Jorquera, 1774-177956

\begin{tabular}{|c|c|c|}
\hline JORQUERA 1774-1779 & Ingreso.rls. & Gastos rls. \\
\hline Curato, primicias, pie de altar & 3546,5 & \\
\hline Cofradía de Ánimas & 240 & \\
\hline Cofradía del Santísimo cera & & 100 \\
\hline Ermita Nuestra Señora Cubas & 685 & 130 \\
\hline Ermita aldea Bormate & 260 & 120 \\
\hline Fábrica parroquial & 3749 & 2759,5 \\
\hline 43 memorias pías & & 740 misas \\
\hline 34 pías memorias & & 84 misas \\
\hline 45 oficios difuntos cantados & & \\
\hline 5 capellanías: & & \\
\hline Alonso Onrrubia/Francisco Armona & & 1 misa \\
\hline $\begin{array}{l}\text { Andrés Gómez Andújar/ } \\
\text { Lucas Morales }\end{array}$ & & 2 misas \\
\hline Pedro Abellán/José Martínez & & 1 misa \\
\hline María de Moya/Miguel Sánchez & & 1 misa \\
\hline Sebastián Gómez/Sebastián Gómez & & 2 misas \\
\hline
\end{tabular}

/ introduce al poseedor

De ello se desprende (y de las tablas 2 y 3 ) que abundaron los fundadores de pías memorias y obras pías, en cuyas listas podemos contemplar a muchos de los miembros de las élites de propietarios locales.

Pueden verse los resultados de los destinatarios de los frutos decimales en tablas 1-3.

\footnotetext{
${ }^{56}$ Informes de D. Joaquín Fernández de Terán, D. Miguel Sánchez Ochando y D. Benito Pérez Pardo, 27.4.1779 y 16.6.1780: ACM, 385/29.
} 
Tabla 2

\begin{tabular}{|c|c|c|c|}
\hline MAHORA 1731/1734 & & JORQUERA 1731/1734 & \\
\hline Primicias & 1168 & Tercias marqués de Villena & 28688 \\
\hline $\begin{array}{l}\text { Ana Villanueva/ } \\
\text { D. José Villanueva }\end{array}$ & 88 & Renta de la fábrica & 1518 \\
\hline D. Juan de las Heras/ídem & 166 & Beneficio curado & 22946 \\
\hline VILLAMALEA 1731 y 1734 & & Terzuelo/rentas de la fábrica & 3016 \\
\hline Renta de la fábrica & 1180 & Primicias de la villa & 648 \\
\hline Diego Rubio/ídem & 72 & $\begin{array}{l}\text { Ermita de Nuestra Señora de } \\
\text { Cubas }\end{array}$ & 244 \\
\hline $\begin{array}{l}\text { Juan Descalzo/ } \\
\text { D. Pedro Fernández }\end{array}$ & 26 & Cofradía de La Asunción & 168 \\
\hline $\begin{array}{l}\text { Andrés Soria, Francisco Garrido/ } \\
\text { D. Andrés Soria }\end{array}$ & 68 & $\begin{array}{l}\text { Alonso Onrrubia/ } \\
\text { D. Esteban Moreno }\end{array}$ & 120 \\
\hline $\begin{array}{l}\text { Juan Descalzo Morales/ } \\
\text { D. José Jiménez }\end{array}$ & 72 & $\begin{array}{l}\text { D. Pedro Abellán/ } \\
\text { D. Miguel Jerónimo Cantos }\end{array}$ & 130 \\
\hline $\begin{array}{l}\text { Francisco Ruiz Amoraga/ } \\
\text { vacante }\end{array}$ & 44 & $\begin{array}{l}\text { María de Moya/ } \\
\text { D. José Medina }\end{array}$ & 322 \\
\hline $\begin{array}{l}\text { Alonso López/ } \\
\text { D. Juan Anto. Caballero }\end{array}$ & 106 & $\begin{array}{l}\text { D. Andrés Gómez/ } \\
\text { D. José Gómez }\end{array}$ & 118 \\
\hline FUENTEALBILLA 1731/1734 & & $\begin{array}{l}\text { Sebastián Gómez/ } \\
\text { D. Pedro Piqueras }\end{array}$ & 198 \\
\hline Renta de fábrica parte diezmos & 1192 & $\begin{array}{l}\text { D. Antonio Cebrián Zapata/ } \\
\text { D. Francisco Peñas Tor }\end{array}$ & 3200 \\
\hline Primicias & 728 & ALATOZ 1731/1734 & \\
\hline $\begin{array}{l}\text { Catalina Cebrián/ } \\
\text { D. José Antonio Martínez }\end{array}$ & 86 & Renta de la fábrica & 728 \\
\hline $\begin{array}{l}\text { Benito Pardo de la Casta/ } \\
\text { Juan de Tévar }\end{array}$ & 70 & Primicias & 418 \\
\hline $\begin{array}{l}\text { Pedro Garrido y consortes/ } \\
\text { D. Roque Garrido }\end{array}$ & 84 & $\begin{array}{l}\text { Ermita Nuestra Señora de las } \\
\text { Nieves }\end{array}$ & 78 \\
\hline $\begin{array}{l}\text { Juan del Campo/ } \\
\text { Ginés de Contreras }\end{array}$ & 32 & MOTILLEJA 1731/1734 & \\
\hline
\end{tabular}




\begin{tabular}{|c|c|c|c|}
\hline ALBOREA 1731/1734 & & Renta de la fábrica & 292 \\
\hline Renta de la fábrica & 1584 & Primicias & 586 \\
\hline Beneficio curado y primicias & 4178 & $\begin{array}{l}\text { Miguel Ruiz Moreno/ } \\
\text { Miguel Moreno Ruiz }\end{array}$ & 1272 \\
\hline Cofradía del Rosario & 202 & ALCALÁ DEL RÍO 1731/1734 & \\
\hline $\begin{array}{l}\text { Martín Chicano y consorte/ } \\
\text { D. Sebastián García }\end{array}$ & 138 & $\begin{array}{l}\text { Tercias del marqués de } \\
\text { Villena }\end{array}$ & 3260 \\
\hline Juan Gómez/Francisco Fuentes & 78 & Renta de la fábrica & 1760 \\
\hline $\begin{array}{l}\text { Pedro La Cuesta/ } \\
\text { D. Francisco de Fuentes }\end{array}$ & 66 & Beneficio préstamo & 2446 \\
\hline $\begin{array}{l}\text { Domingo Gómez, Gonzalo } \\
\text { Segovia/Francisco Monsalve }\end{array}$ & 44 & Beneficio curado & 3192 \\
\hline $\begin{array}{l}\text { Sebastián García, D. Juan Pando/ } \\
\text { D. Francisco Ruiz }\end{array}$ & 32 & Abadía de San Lorenzo & 354 \\
\hline $\begin{array}{l}\text { Pascual López, Francisca } \\
\text { Delgado/Bartolomé Bolincher }\end{array}$ & 598 & $\begin{array}{l}\text { Alonso Valiente/ } \\
\text { D. Pedro Martínez }\end{array}$ & 16 \\
\hline Tercias de marqués de Villena & 2200 & $\begin{array}{l}\text { Bárbara Pérez/ } \\
\text { Pascual Pérez }\end{array}$ & 278 \\
\hline $\begin{array}{l}\text { D. Sebastián García Moya/ } \\
\text { D. Pascual Pérez Ayala }\end{array}$ & 142 & $\begin{array}{l}\text { Juan López Rosillo/ } \\
\text { D. Antonio García Valero }\end{array}$ & 394 \\
\hline $\begin{array}{l}\text { D. Francisco de Fuentes/ } \\
\text { Juan Fernández Valiente }\end{array}$ & 1726 & Benito Pérez/Pascual Pérez & 16 \\
\hline CASAS IBÁÑEZ 1731/1734 & & Juan Sáez/D. Pedro Piqueras & 294 \\
\hline Renta de la fábrica & 1796 & $\begin{array}{l}\text { Cristóbal Cebrián/ } \\
\text { Pedro Cebrián Torre }\end{array}$ & 1358 \\
\hline Primicias & 1350 & $\begin{array}{l}\text { D. Antonio Zapata/ } \\
\text { D. Francisco Las Peñas }\end{array}$ & 576 \\
\hline Cofradía de Santa Catalina & 274 & $\begin{array}{l}\text { Cristóbal González Ochando/ } \\
\text { Juan Albertos }\end{array}$ & 152 \\
\hline $\begin{array}{l}\text { Juan de Soto, Juan López Valero/ } \\
\text { Juan de la Jara }\end{array}$ & 192 & $\begin{array}{l}\text { D. Antonio Zapata/ } \\
\text { D. Antonio Sánchez }\end{array}$ & 364 \\
\hline $\begin{array}{l}\text { Andrés López Cañavate/ } \\
\text { D. Juan A. Cañavate }\end{array}$ & 118 & GOLOSALVO 1731/1734 & \\
\hline
\end{tabular}




\begin{tabular}{|c|c|c|c|}
\hline $\begin{array}{l}\text { Isabel Soriano/ } \\
\text { D. Andrés Ochando }\end{array}$ & 214 & Renta de la fábrica & 244 \\
\hline Ginés Prieto/D. Carlos Prieto P. & 146 & Primicias & 424 \\
\hline $\begin{array}{l}\text { D. Ginés Pérez/ } \\
\text { D. Antonio Medina }\end{array}$ & 96 & CARCELÉN 1731/1734 & \\
\hline $\begin{array}{l}\text { Bartolomé Villena, J. Martínez/ } \\
\text { Martín Jara }\end{array}$ & 86 & $\begin{array}{l}\text { Diezmos del señor de } \\
\text { Carcelén }\end{array}$ & 1772 \\
\hline $\begin{array}{l}\text { Antonio Gómez, Francisco } \\
\text { Lajara/ Andrés Gómez }\end{array}$ & 328 & Primicias & 602 \\
\hline $\begin{array}{l}\text { Juan Jiménez Espinosa/ } \\
\text { Andrés J. Orozco }\end{array}$ & 326 & $\begin{array}{l}\text { Martín Delgado/ } \\
\text { D. Juan Martínez }\end{array}$ & 38 \\
\hline $\begin{array}{l}\text { Ginés Prieto/ } \\
\text { D. Pascual Prieto Ruiz }\end{array}$ & 102 & $\begin{array}{l}\text { Francisco López Pardo/ } \\
\text { Marcos López }\end{array}$ & \\
\hline $\begin{array}{l}\text { Cristóbal Gómez/ } \\
\text { D. Pascual Gómez }\end{array}$ & 142 & VES $1731 / 1734$ & \\
\hline $\begin{array}{l}\text { Ginés López Risueño/ } \\
\text { D. Juan de la Jara }\end{array}$ & 58 & Terzuelo/renta de la fábrica & 2566 \\
\hline $\begin{array}{l}\text { lcdo. Miguel Sáiz/ } \\
\text { D. Pascual Gómez Ochando }\end{array}$ & 132 & Beneficio curado & 4994 \\
\hline $\begin{array}{l}\text { Gonzalo de Medina/ } \\
\text { D. José García Valero }\end{array}$ & 144 & Beneficio préstamo & 3176 \\
\hline VALDEGANGA 1731/1734 & & $\begin{array}{l}\text { Ermita Nuestra Señora de la } \\
\text { Encarnación }\end{array}$ & 222 \\
\hline Renta de la fábrica & 620 & Ermita de San Sebastián & 52 \\
\hline Primicias & 690 & $\begin{array}{l}\text { Pascual Carrión/ } \\
\text { D. Diego Pérez }\end{array}$ & 152 \\
\hline Abadía de San Benito & 430 & $\begin{array}{l}\text { Juan Gómez, Francisca } \\
\text { Navarro/ D. Diego P. }\end{array}$ & 162 \\
\hline $\begin{array}{l}\text { Álvaro Calderón/ } \\
\text { D. José Calderón }\end{array}$ & 2456 & $\begin{array}{l}\text { Antón de Fuentes/ } \\
\text { D. Juan Ochando }\end{array}$ & 658 \\
\hline ABENGIBRE 1731/1734 & & $\begin{array}{l}\text { Pascual Serrano/ } \\
\text { D. Juan García }\end{array}$ & 136 \\
\hline Renta de la fábrica & 398 & $\begin{array}{l}\text { Obispo Rojas/ } \\
\text { D. Pedro Vicente }\end{array}$ & 1060 \\
\hline Primicias & 386 & $\begin{array}{l}\text { Cristóbal Navarro/ } \\
\text { D. José Antonio Martínez }\end{array}$ & 192 \\
\hline
\end{tabular}




\begin{tabular}{|l|l|l|c|}
\hline Primicias Casas de Juan Núñez & 238 & POZO LORENTE 1731/1734 & \\
\hline & & Renta de la fábrica & 194 \\
\hline & & Primicias & 182 \\
\hline & & M. Villena/Jmo. Villena & 36 \\
\hline
\end{tabular}

Fuente: Archivo Catedralicio de Murcia, Cuentas de diezmos

Tabla 3

\begin{tabular}{|c|c|c|c|}
\hline ALCALÁ DEL RÍO 1771-72 & Subsid & & \\
\hline Renta de la fábrica & 1744 & 1744 & \\
\hline Tercias del marqués de Villena & 3226 & 3226 & \\
\hline Beneficio curado & 3158 & 3158 & \\
\hline beneficio préstamo D. Juan Carrión & 2420 & 2420 & \\
\hline Abadía de San Lorenzo & 350 & 350 & \\
\hline $\begin{array}{l}\text { Capellanía Alonso Valiente/ } \\
\text { Pedro Martínez }\end{array}$ & 16 & 16 & \\
\hline $\begin{array}{l}\text { Id Juan López Rosillo/ } \\
\text { D. Gaspar García }\end{array}$ & 392 & 392 & \\
\hline Id Bárbara Pérez & 276 & 276 & \\
\hline $\begin{array}{l}\text { Id Juan Sáez/ } \\
\text { D. Bartolomé Villaescusa }\end{array}$ & 292 & 292 & \\
\hline $\begin{array}{l}\text { Id Cristóbal Cebrián/ } \\
\text { D. Pedro Cebrián }\end{array}$ & 1344 & 1344 & \\
\hline $\begin{array}{l}\text { Id D. Antonio Zapata/ } \\
\text { D. Juan González Carrión }\end{array}$ & 570 & 570 & \\
\hline $\begin{array}{l}\text { Id Cristóbal González y } \\
\text { Alonso Ochando }\end{array}$ & 150 & 150 & D. Andrés Espinosa \\
\hline
\end{tabular}




\begin{tabular}{|c|c|c|c|}
\hline $\begin{array}{l}\text { Id Antonio Zapata/ } \\
\text { D. Juan González Carrión }\end{array}$ & 360 & 360 & \\
\hline ALBOREA 1771-72 & Subsid & & \\
\hline Renta de la fábrica & 1620 & 1620 & \\
\hline beneficio curado & 4260 & 4260 & \\
\hline $\begin{array}{l}\text { Cofradía Nuestra Señora del } \\
\text { Rosario }\end{array}$ & 200 & 200 & \\
\hline $\begin{array}{l}\text { Capellanía Martín Chicano, } \\
\text { Ángela Gómez }\end{array}$ & 76 & 136 & $\begin{array}{l}\text { D. Antonio Cerezo } \\
\text { Montixo }\end{array}$ \\
\hline $\begin{array}{l}\text { Id Pedro de Cuesta/ } \\
\text { D. Juan Sánchez }\end{array}$ & 66 & 66 & \\
\hline Domingo Gómez, Gonzalo Segovia & 44 & 44 & D. Francisco Valiente \\
\hline Sebastián García, D. Juan Pando & 30 & 30 & D. Miguel Delgado \\
\hline Pascual López, Francisco Delgado & 594 & 594 & D. Miguel Delgado \\
\hline D. Sebastián García Moya & 140 & 140 & D. Pascual Pérez \\
\hline D. Francisco Fuertes/D. Blas Pérez & 740 & 740 & \\
\hline Tercias del marqués de los Vélez & 2262 & 2262 & \\
\hline $\begin{array}{l}\text { Capellanía Martín Chicano, } \\
\text { Ángela Gómez }\end{array}$ & 136 & & D. Patricio Chicano \\
\hline VES Y SUS CASAS 1771-72 & Subsid & & \\
\hline Renta de la fábrica & 2536 & 2536 & \\
\hline Beneficio curado & 5030 & 5030 & \\
\hline Beneficio préstamo & 3144 & 3144 & \\
\hline $\begin{array}{l}\text { Ermita de Nuestra Señora } \\
\text { Encarnación }\end{array}$ & 220 & 220 & \\
\hline
\end{tabular}




\begin{tabular}{|c|c|c|c|}
\hline Ermita de San Sebastián & 50 & 50 & \\
\hline \multicolumn{2}{|c|}{ Capellanía Juan Gómez Francisco Navarro } & 160 & D. Diego Carrión \\
\hline Pascual Carrión/D. Diego Carrión & 150 & 150 & \\
\hline Antonio Fuentes, Tomás Ochando & 652 & 652 & D. Juan García Argente \\
\hline Pascual Serrano & 134 & 134 & D. Juan García Argente \\
\hline Obispo Rojas & 1050 & 1050 & D. Juan Carrión \\
\hline Cristóbal Navarro, Miguel Cuesta & 192 & 192 & D. José Martínez \\
\hline ALATOZ 1771-72 & Subsid & & \\
\hline Primicias & 276 & 276 & \\
\hline $\begin{array}{l}\text { Ermita de Nuetra Señora de las } \\
\text { Nieves }\end{array}$ & 76 & 76 & \\
\hline POZO LORENTE 1771-72 & Subsid & & \\
\hline Primicias & 180 & 180 & \\
\hline CARCELÉN 1771-72 & Subsid & & \\
\hline Diezmos del señor de Carcelén & 1810 & 1810 & \\
\hline Primicias & 598 & 598 & \\
\hline $\begin{array}{l}\text { Capellanía María Villena/ } \\
\text { D. Pedro Gómez }\end{array}$ & 34 & 34 & \\
\hline Id Martín Delgado & 36 & 36 & \\
\hline $\begin{array}{l}\text { Francisco López Pardo/ } \\
\text { Juana García }\end{array}$ & 386 & 386 & D. Marcos \\
\hline ABENGIBRE 1771-72 & Subsid & & \\
\hline
\end{tabular}




\begin{tabular}{|c|c|c|c|}
\hline Primicias & 412 & 412 & \\
\hline CASAS DE JUAN NÚÑEZ 1771-72 & Subsid & & \\
\hline Primicias & 220 & 220 & \\
\hline ARCIPRESTE JORQUERA 1771/72 & Subsid & & \\
\hline Tercias del marqués de Villena & 22704 & 22704 & \\
\hline Beneficio curado & 22704 & 22704 & \\
\hline Renta de la fábrica & 12744 & 12744 & \\
\hline Primicias & 748 & 748 & \\
\hline Renta de Nuestra Señora de Cubas & 242 & 242 & \\
\hline $\begin{array}{l}\text { Cofradía de Nuestra Señora de } \\
\text { Asunción }\end{array}$ & 166 & 166 & \\
\hline $\begin{array}{l}\text { Capellanía Onrrubia/ } \\
\text { D. Pascual Vergara }\end{array}$ & 118 & 118 & \\
\hline $\begin{array}{l}\text { D. Pedro Abellán/ } \\
\text { D. José Martínez Abellán }\end{array}$ & 128 & 128 & \\
\hline María Moya/D. Pedro Medina & 318 & 318 & \\
\hline Sebastián Gómez/D. José Piqueras & 196 & 196 & \\
\hline CASAS IBÁÑEZ 1772 & Subsid & 101804 & \\
\hline Primicias & 1338 & & \\
\hline $\begin{array}{l}\text { Capellanía Santa Catalina/ } \\
\text { D. Juan Pérez Lajara }\end{array}$ & 272 & & \\
\hline Juan Soto, Juan López/D. Juan Jara & 190 & & \\
\hline $\begin{array}{l}\text { Andrés Cañavate/ } \\
\text { Quiteria Pérez Cañavate }\end{array}$ & 118 & & \\
\hline
\end{tabular}




\begin{tabular}{|c|c|c|}
\hline $\begin{array}{l}\text { Isabel Ochando/ } \\
\text { D. Andrés Ochando }\end{array}$ & 212 & Ginés Valero \\
\hline $\begin{array}{l}\text { D. Ginés Prieto/ } \\
\text { D. Carlos Prieto Pérez }\end{array}$ & 146 & Pascual Prieto \\
\hline Antonio Gómez, Francisco Jara & 326 & $\begin{array}{l}\text { Antonio Gómez } \\
\text { Martínez }\end{array}$ \\
\hline $\begin{array}{l}\text { D. Ginés Pérez/ } \\
\text { D. Alonso García Otazo }\end{array}$ & 96 & Beatriz Orozco \\
\hline $\begin{array}{l}\text { Juan Jiménez Espinosa/ } \\
\text { D. Andrés J. Orozco }\end{array}$ & 324 & Pedro Jiménez Espinosa \\
\hline Ginés Prieto/D. Carlos Prieto Pérez & 102 & Pascual Prieto \\
\hline Cristóbal Gómez, Alfonsa García & 142 & D. Alonso de Soto \\
\hline $\begin{array}{l}\text { Ginés López Risueño/ } \\
\text { Juan de la Jara }\end{array}$ & 56 & Juan Pérez de la Jara \\
\hline $\begin{array}{l}\text { Miguel Sáez/ } \\
\text { D. Alonso de Sotos López }\end{array}$ & 132 & \\
\hline $\begin{array}{l}\text { Gonzalo Medina/ } \\
\text { D. Martín García Valero }\end{array}$ & 144 & \\
\hline CENIZATE 1772 & Subsid & \\
\hline Primicias & 714 & \\
\hline Memoria del curato & 70 & \\
\hline Miguel García y consortes & 50 & \\
\hline Dạ María Núñez & 34 & \\
\hline $\begin{array}{l}\text { Morales y sus hijos/ } \\
\text { José Ruiz Alarcón }\end{array}$ & 194 & \\
\hline VILLAMALEA 1772 & Subsid & \\
\hline Primicias & 1378 & \\
\hline $\begin{array}{l}\text { Capellanía Pedro Alcantud/ } \\
\text { Alonso Martínez }\end{array}$ & 54 & \\
\hline
\end{tabular}




\begin{tabular}{|l|l|l|l|}
\hline $\begin{array}{l}\text { Juan Oliver/ } \\
\text { D. Juan Cuadrado presbítero }\end{array}$ & 66 & & \\
\hline Diego Rubio/vacante & 70 & & \\
\hline Andrés Soria, Francisco Garrido & 68 & & D. Jorge Garrido \\
\hline $\begin{array}{l}\text { Juan Descalzo Morales/ } \\
\text { D. Juan Alarcón }\end{array}$ & 70 & & \\
\hline $\begin{array}{l}\text { Francisco Ruiz Amoraga/ } \\
\text { D. Blas Cuesta }\end{array}$ & 44 & & \\
\hline VALDEGANGA 1772 & 684 & & \\
\hline Primicias & 426 & & \\
\hline Abadía de San Benito & 102 & & D. José Calderón \\
\hline Álvaro Calderón, Quiteria Neras & & & \\
\hline
\end{tabular}

Fuente: Archivo Catedralicio de Murcia, Cuentas de diezmos

Muchos perceptores eran presbíteros o sacerdotes y sólo alguno diácono o laico. Se puede concluir además que la documentación conservada coincide con periodos de mayor presión, por razón de guerras que exigieron un mayor esfuerzo.

Por ejemplo en 1817, en paralelo a la instauración de la contribución extraordinaria del ministro Martín de Garay, se introdujo un nuevo subsidio, para el que se pidió información a los presbíteros de sus rentas y las de las parroquias y capellanías en el quinquenio 1805-1807/1815-1816, pues de los años de la Guerra de Independencia (1808-1814) se consideró imposible a causa de los daños sufridos.

En Jorquera se documentaron las capellanías fundadas por Juan Antonio Belmonte (poseedor Juan José Belmonte Pérez), con renta anual de 1.490 reales de tierras (una huerta de 10 celemines en el Almarche arrendada por 600 reales, otra de 9 en id por 500, otra de 2,5 celemines en la Recueja por 160 y otra de 4,5 en los Tor- 
najos por 230) y 1.496 de fincas enajenadas en la desamortización de Godoy por un capital de 19.361 reales, con unas cargas de misas y contribuciones de 226,3057. En 1829, seis años después del Trienio Liberal, se procedió contra deudores del subsidio de Jorquera, Carcelén, Golosalvo, Casas de Ves, Alcalá del Río, Abengibre y Casas de Juan Núñez ${ }^{58}$, como sucedió en otros dezmatorios.

\section{LA VILLA DE VES Y SU TIERRA: LA GESTIÓN DE SU DIEZMO}

Ves fue villa realenga, no perteneciente al estado de Jorquera. En 1575 el beneficiado Jusepe de Tórtola promovió una información de testigos sobre la necesidad de tercia en la villa, ante el alcalde ordinario Cristóbal Gómez y el escribano Hernando Cebrián ${ }^{59}$.

En Ves había varias aldeas, como Casas de Ves, en la que se alquilaban locales ${ }^{60}$.

Su contribución militar fue parecida a la de Jorquera: en 1646 al servicio de milicias del Reino de Murcia con 5 soldados y 1320 reales. Ves tuvo 117 vecinos en 1530, 218 en 1591 y 197 en 1646; en 1618/1642 se le adjudicaron 20/4 soldados (Ruiz, 1994, p. 793).

Hubo tensiones entre Ves, población estrecha y montuosa, y su aldea Casas de Ves, zona llana, como la de Aledo con su arrabal Totana (Griñán, 1991), o Jorquera con respecto a Mahora, pero hay también información de su contribución eclesiástica ${ }^{61}$.

\footnotetext{
${ }^{57}$ ACM, 533/26, 5, 1819.

${ }^{58}$ ACM, 515/10.

${ }^{59}$ Exposición en probanza por petición del Beneficiado Tórtola, clérigo de Ves, sobre las tercias de aquella villa: ACM, 789/38, n. 1, 1575.

${ }^{60}$ primer testigo de 4 , ídem.

${ }^{61}$ En 1620 se recogieron de diezmo 440/99 fanegas de trigo y 749/164,3 de centeno, 140/31'5 libras de queso, 50 arrobas/11, 6 libras y 4 onzas de lana, 50 arrobas/11-6-4 de miel y 60/13'5 libras de cera y 300/67,5 cabezas de ganado, es decir entró en esa media de $3 / 4$ de cereales. La parte del ganado del cabildo se vendió mediante subasta a Ginés Pérez, vecino de Alcalá del Río a 8,5 reales: licenciado José de Tórtola, Francisco García Sánchez y Alonso Tomás de Madrona y Monteagudo, 4.10, 2.6 y 2.5.1620: ACM, 363/57.
} 
El presbítero cura de Ves Doctor Jusepe de Tórtola consiguió el 3.8.1635 una sentencia del nuncio que le amparó en su derecho a tener la llave de la tercia decimal del pueblo, a llevar libro de tercia y a cobrar el tercio del rediezmo, en pie de igualdad con los colectores del rey y del obispo, en apelación de una sentencia de este último ${ }^{62}$, coincidiendo con Jorquera en su conflicto con el marqués de Villena. La ejecutoria original se notificó a Miguel Martínez Sanmartín y Juan Carrión, fieles del rey y el obispo, «que al parecer entonces eran fieles los alcaldes ordinarios», y en 1638 a Esteban Pardo Moro y Pedro Martínez de Cuevas. Esta observación entrecomillada es muy interesante pues muestra la identidad en este caso entre unos y otros y probablemente personas principales. Es un ejemplo de las tensiones por intereses económicos que se producían en torno a la administración de los diezmos, que se reguló minuciosamente desde las constituciones de los obispos Nicolás de Aguilar y Diego de Comontes, pero en la que se sucedieron abusos y conflictos.

En 1641 y 1662 se hicieron tazmías de vino separadas, en las que se aprecia aún una diferencia a favor de $\mathrm{Ves}^{63}$.

En 1684-1685 Ves reclamó y obtuvo ejecutoria contra la tercia de Casas de Ves, por salir Ves perjudicada. Las visitas de 1688, 1726 y 1772 , espaciadas, provocaron quejas y litigios, pues el obispo y cabildo eclesiástico pleitearon en 1726-1728 con los vecinos y cosecheros de hoja de seda de la villa de Ves y el lugar de Casas de Ves por no pagar diezmo ${ }^{64}$, y aún se reclamaron contra mandatos de

\footnotetext{
${ }^{62}$ Sentencia de 1.7.1634. Traslado de ejecutoria de Cuenca, 3.8.1635 en Ves, 29.7.1743. ACM, 772/31.

${ }^{63}$ En Ves en 1641 correspondieron al cabildo 87 arrobas y 6 azumbres de un total de 390 arrobas, y en Casas de Ves 11 arrobas a 6 reales (66) en 1662: Certificaciones de Pedro Martínez de Cuevas, presbítero, por Juan Fernández y Miguel Martínez de Sanmartín, fieles, Ves, 1.5.1642; Francisco Martínez Maldonado, Jorquera, 11.5.1642; Miguel García de Ochandiano, Carcelén, 8.12.1642: ACM (García, 2014), 764/26. Víd. Almendros, 1989, p. 26-27 y 34.

${ }^{64}$ Autos judiciales de 1728 por contravención de un auto de la visita de Pedro Guitarte de 7.10.1688, había 1903 moreras, 156 de más de 40 años en Ves y 1100 en Casas de Ves, 13 antiguas, sin hacerse visita de 1688 a 1726: ACM, 789/38, 7. Este tipo de pleito se dio en Yecla con el aceite.
} 
visitadores, en que se alegó que los labradores de algunas aldeas se nutrían para simiente de los granos menores y por lo tanto la lejanía de la tercia más cercana les producía sobrecostes y perjuicios, o del cura párroco en 1744 y al cabildo catedralicio en 1775 y 1786. Algunos vecinos de Villa de Ves pleitearon con el Cabildo de Murcia sobre el pago del diezmo de cera y miel ${ }^{65}$.

\section{CONCLUSIONES}

La historia del estado señorial de Jorquera y de Ves y su tierra puede ser abordada desde otras fuentes que las locales, como aquí se procura. Estas fuentes dan testimonio de diversos individuos y comunidades, aglutinados en familias, lugares o aldeas con ermitas generalmente, capaces de generar una producción y unas relaciones de negocio y patrimonio. Negocios se hicieron en torno a los cereales, principal producto, del que su necesidad obligó a comprarlo incluso a las tercias eclesiásticas, pero también en torno a la tierra y sus frutos: azafrán, cáñamo, cereal, vino, etc., y en relación al ganado, necesario para el laboreo agrícola, para el abasto de carne o para el transporte.

El río Júcar modeló un paisaje irregular, de hoces, con Jorquera en un alto, en razón de su defensa, o en una zona angosta en el caso de Ves, por lo que en ambos proliferaron las aldeas, en las que se instalaron algunas tercias de diezmos y viñedos, con que se extendieron asimismo heredades y bancales y especialidades en azafrán o en queso, que enriquecieron la variedad de sus producciones.

Esta explotación del terreno llevó a tensiones entre labradores productores y perceptores eclesiásticos de diezmos, en que intervino el marqués de Villena como señor del estado de Jorquera, o el rey en el de Ves y su tierra. Tales tensiones y conflictos aumentaron con el paso del tiempo y caracterizaron singularmente la evolución histórica moderna. De ellas han quedado testimonios materiales en los documentos de archivos, que se diversificaron según

${ }^{65}$ AHN, Consejos, 31545/1 y 31780/7, 1768-1771 y 1743-1761. 
fueran los propietarios de archivos, pues cada uno utilizó medios y argumentos propios e interesados, por lo que hay que considerarlos críticamente, en atención a su posición en un conjunto. 


\section{REFERENCIAS BIBLIOGRÁFICAS}

AGUIRRE LANDA, I. (1996). Fuentes documentales sobre Murcia en el Archivo de Simancas. Cuadernos del Seminario Floridablanca, (3), 53-72.

ALMENDROS TOLEDO, J. M. (1987). Apuntes para el estudio de la extinción del Señorío de Jorquera. En A. Pretel Marín (Coord.), Congreso de Historia del Señorío de Villena (Albacete, 2326.10.1986). (pp. 27-44). Instituto de Estudios Albacetenses «Don Juan Manuel».

ALMENDROS TOLEDO, J. M. (1989). Ordenanzas municipales de la Ribera del Júcar: Villa de Ves (1589) y Jorquera (1721). Instituto de Estudios Albacetenses «Don Juan Manuel».

ALMENDROS TOLEDO, J. M. (1994). La Iglesia Parroquial de San Miguel Arcángel, de Abengibre. Ensayos, Revista de la Facultad de Educación de Albacete, (9), 17-30.

ALMENDROS TOLEDO, J. M. (2002). Villatoya, la larga y costosa disolución de una propiedad señorial. En C. Panadero Moya y M. Requena Gallego (Coords.), II Congreso de Historia de Albacete. IV Edad Contemporánea. (pp. 63-80). Instituto de Estudios Albacetenses «Don Juan Manuel».

ALMENDROS TOLEDO, J. M. (2005). División del curato de Jorquera en el año 1722 por el cardenal Belluga y creación de trece nuevas parroquias en su término. Al-Basit Revista de Estudios Albacetenses, (49), 129-160.

ALMENDROS TOLEDO, J. M. (2009). Al Nordeste, el Estado de Jorquera. En L.G. García-Saúco Beléndez (Coord.). Cultural Albacete, (vol. 2, pp. 255-263). Instituto de Estudios Albacetenses «Don Juan Manuel».

ALMENDROS TOLEDO, J. M. (2018). Cuarto centenario de las fiestas patronales de Casas Ibáñez (1617-2017): espejos de una feria. Al-Basit Revista de Estudios Albacetenses, (63), 277-310. cretaría de Gracia y Justicia. Cuadernos de Historia Moderna, (15), 279-296. 
ANDÚJAR CASTILLO, F. (1999). Los genoveses en el Reino de Granada: comercio y estrategias mercantiles. En E. Belenguer Cebriá (Coord.), Felipe II y el Mediterráneo. (vol. 1, pp. 357376). Sociedad para la Conmemoración de los Centenarios de Felipe II y Carlos V.

ANDÚJAR CASTILLO, F. (2005). Huéscar en el siglo de Oro: los mercaderes genoveses. En J. P. Díaz López (Ed.), Campesinos, nobles y mercaderes. Huéscar y el Reino de Granada en los siglos XVI y XVII (pp. 17-32). Ayuntamiento de Huéscar.

CANO VALERO, J. (1979). El Estado de Jorquera en los documentos del RGS (1476-1488). Anales del Centro Asociado de Albacete, (1), 179-200.

CANO VALERO, J. (1984). Intentos frustrados de villazgo y exención jurisdiccional del lugar de Villamalea en el siglo XVII. Al-Basit Revista de Estudios Albacetenses, (13), 25-36.

CANO VALERO, J. (1992). El régimen señorial castellano en el antiguo régimen. La pervivencia de la jurisdicción de los Marqueses de Villena en las villas de Jorquera y Alcalá del Río Júcar (14751812) (Tesis doctoral. Universidad de Murcia.)

CANO VALERO, J. (Coord.) (2017). Villamalea: retazos de historia y de la vida de sus gentes. Instituto de Estudios Albacetenses «Don Juan Manuel».

CARPENA CHINCHILLA, F. J. (2019). Una suma de voluntades. La construcción de la Basílica de la Purísima de Yecla (17721868). CEL Yecla.

CRUZ HERRANZ, L.M. (1996). La organización de los fondos en el Archivo Histórico Nacional (1866-1989). Boletín de la ANA$B A D,(46,1), 65-94$.

CRUZ MUNDET, J.R. (1997). La enseñanza de la Archivística en la universidad española. Revista General de Información y Documentación, (7/1), 321-328.

DIAGO HERNANDO, M. (2013). Bartolomé Arnolfo, un saboyano en el Madrid del siglo XVII, financiero, mercader y señor de ganados. Studia Histórica (Hª Moderna), (35), 371-407. 
DURANTI, L. (1996). Diplomática: usos nuevos para una antigua ciencia. S\&C ediciones.

FRANCO SILVA, A. (1993-1994). Jorquera y Alcalá del Júcar a fines del Medievo: dos villas del marquesado de Villena. Miscelánea Medieval Murciana, (18), 23-38.

FRANCO SILVA, A. (2007). La pérdida definitiva del marquesado de Villena. Don Diego II López Pacheco. Universidad de Cádiz.

FUENTE COBOS, C. (1995). La documentación de Patronato Eclesiástico de Castilla. Hispania Sacra, (96), 625-679.

GARCÍA DÍAZ, I. (2014). El origen del Archivo de la Catedral de Murcia: el inventario de 1536. Historia, Instituciones, Documentos, (41), 205-242.

GARCÍA OLMO, M.A., IRIGOYEN LÓPEZ, A. y GARCÍA HOURCADE, J.J. (2002). Albacete en los documentos episcopales durante la Edad Moderna. En A. Santamaría Conde, L.G. García Saúco y J. Sánchez Ferrer (Eds.), II Congreso de Historia de Albacete. III Historia Moderna. (pp. 217-225). Instituto de Estudios Albacetenses «Don Juan Manuel».

GARCÍA VILLADA, Z. (1921). Metodología y crítica históricas. Juan Gili.

GIRÓN PASCUAL, R. M. (2005). Mercaderes milaneses y regidores de Huéscar en el siglo XVI: los Cernúsculo. En J. P. Díaz López (Ed.), Campesinos, nobles y mercaderes. Huéscar y el Reino de Granada en los siglos XVI y XVII. (pp. 51-74). Ayuntamiento de Huéscar.

GIRÓN PASCUAL, R. M. (2012). Las indias de Génova. Mercaderes genoveses en el reino de Granada durante la Edad Moderna (sS. XVI-XVIII). (Tesis doctoral. Universidad de Granada).

GÓMEZ VOZMEDIANO, M.F. (2017). El Archivo Histórico de la Nobleza. Boletín de la ANABAD, (67/1), 15-32.

GRIÑÁN MONTEALEGRE, M. (1991). Totana, una nueva ciudad del Quinientos. Ayuntamiento de Totana.

IRIGOYEN LÓPEZ, A. (2005). Un obispo, una diócesis, un clero: Luis Belluga, prelado de Cartagena. Real Academia Alfonso X el Sabio. 
LAFUENTE URIÉN, A. (2000). Archivos nobiliarios conservados en centros públicos. Boletín de la ANABAD, (50/2), 39-54.

LEMEUNIER, G. (1983). La coyuntura murciana: población y producción en el Siglo de Oro (1500-1650). Cuadernos de Historia de España, Anexos, (X), 165-233.

LEMEUNIER, G. (1987). Crecimiento agrícola y roturaciones en el antiguo marquesado de Villena (s. XVIII). Al-Basit Revista de Estudios Albacetenses, (21), 5-31.

LEMEUNIER, G. (2011). La apicultura en Francia y España entre los siglos XVIII y XIX. Historia Agraria, (54), 17-40.

LÓPEZ BELINCHÓN, B.J. (2001). Sacar la sustancia al reino. Comercio, contrabando y conversos portugueses, 1621-1640. Hispania Revista Española de Historia, (209), 1017-1050.

LÓPEZ GÓMEZ, P. (1998). Los archiveros y sus investigaciones. Métodos de Información, (5, 22-23), 37-43.

MARTÍNEZ CARRILLO, M. Ll. (1987). El marquesado de Villena a través de documentos murcianos, 1369-1449. Instituto de Estudios Albacetenses «Don Juan Manuel».

MIÑANO, S. (1827). Diccionario Geográfico Estadístico de España y Portugal. T.V. Imprenta de Pierart-Peralta.

MITRE, E. (1969). Señorío y frontera: el marquesado de Villena entre 1386 y 1402. Murgetana Revista de la Academia Alfonso X el Sabio, (30), 55-62.

MOLINA MOLINA, A. L., SELVA INIESTA, A. (1996). Carta de mayorazgo de Agramón. Al-Basit Revista de Estudios Albacetenses, (39), 99-116.

MOLINA PUCHE, S., ORTUÑO MOLINA, J. (2009). Los Grandes de Murcia: los Marqueses de Villena. Caída y auge de una casa aristocrática. Real Academia Alfonso X El Sabio.

MONTOJO MONTOJO, V. (2007). El archivo objeto de la archivística: El Archivo Histórico Provincial de Murcia en su 50 aniversario. Murgetana, Revista de la Real Academia Alfonso X el Sabio, (117), 169-187. 
MONTOJO MONTOJO, V. (2008). Los comerciantes de Alicante y Cartagena en la Guerra de Sucesión. Estudis. Revista de Historia Moderna, (34), 219-239.

MONTOJO MONTOJO, V. (2018). Notas históricas de linajes de Tobarra y Hellín en 1578-1590. Al-Basit Revista de Estudios Albacetenses, (63), 69-90.

MUÑOZ NAVARRO, D. (2007). Fraude en el comercio de seda entre los reinos de Castilla y Valencia en la época de Felipe II. Olea$n a,(22), 593-611$.

MUÑOZ NAVARRO, D. (2015). Per camins inussitats i sendes molt apartades. Contrabando de seda valenciana hacia Castilla en la segunda mitad del siglo XVI. Revista de Historia Moderna, (33), 229-241.

MUÑOZ RODRÍGUEZ, J. D. (2003). Damus ut des. Los servicios de la ciudad de Murcia a la Corona a fines del siglo XVII. Real Academia Alfonso X el Sabio.

ORTUÑO MOLINA, J. (2002). Evolución espacial y jurisdiccional de la Tierra de Alarcón. En Littera scripta in honorem profesor Lope Pascual Martínez. (v. 2, pp. 777-788). Universidad de Murcia.

ORTUÑO MOLINA, J. (2003). La incorporación del Marquesado de Villena a la corona de Castilla en el reinado de los Reyes Católicos. Universidad de Murcia.

PASCUAL GONZALO, B. (2002). Archivo Histórico Provincial de Albacete: nuevas posibilidades de investigación (identificación archivística e historia institucional). En C. Panadero Moya y M. Requena Gallego (Coords.), II Congreso de Historia de Albacete. IV Historia Contemporánea. (pp. 465-479). Instituto de Estudios Albacetenses «Don Juan Manuel».

PASCUAL MARTÍNEZ, J. (2018). Los moriscos antiguos murcianos. Expulsión, vuelta y permanencia (Tesis doctoral. Universidad de Murcia).

RODRÍGUEZ DE DIEGO, J. L. (2007). Importancia histórica del contenido del Archivo General de Simancas. Anales de Mecánica y Electricidad, (84, 2), 55-63. 
ROMERO GONZÁLEZ, J. (1981). Documentación existente en el Archivo General de Simancas sobre venta de bienes de patrimonio real de la actual provincia de Albacete (años de 1557 a 1805). Al-Basit Revista de Estudios Albacetenses, (9), 207210.

RUIZ IBÁÑEZ, J. J. (1994). Las dos caras de Jano (Tesis Doctoral. Universidad de Murcia).

SÁNCHEZ FERRER, J., CANO VALERO, J. (1989-1990). Descentralización de la manufactura textil en Villamalea a principios del siglo XVII. Anales del Centro Asociado de Albacete, (10), 175187.

SÁNCHEZ FERRER, J. (2010). Territorio, población y aprovechamiento de la tierra en el municipio de Chinchilla a mediados del siglo XVIII. En L.G. García-Saúco Beléndez (Coord.), Cultural Albacete. (vol. 3, pp. 344-356). Instituto de Estudios Albacetenses «Don Juan Manuel».

SIMÓN GARCÍA, M. M. (2009). Familias, propiedad y grupos sociales en Jorquera. Estructuras sociales de la población a mediados del siglo XVIII. Investigaciones Históricas, (29), 129-152.

TORRES FONTES, J. (1953). El Obispado de Cartagena en el siglo XIII. Hispania Revista Española de Historia, (52), 339-401. 